\title{
المسُسنعِف الأخير وفائض السيولة في المصارف الإسلامية
}

هناء محمد الحنيطي

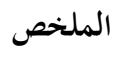

تتناول هذه الدراسة بيان مفهوم المُسنعِف الأخير وعلاقته بالمصارف الإسلامية؛ إذْ يُعَلُّ عدم وجود المُسنعِف

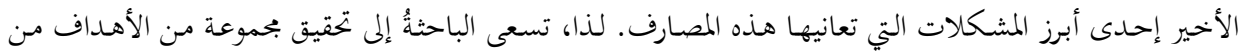
خلال هذه الدراسة، تتمثّل في بيان مفهوم المُسنعِفِ الأخير ووظيفته، والبدائل والحلول المقترحة القابلة للتطبيق، التي

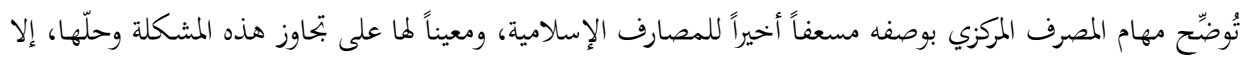
أنّ الاختلاف بين خصائص النظم المصرفية المختلطة والنظم المصرفية الإسلامية، قد أظهر تمايزاً لبعض هذه البـائل وأفضلية على غيرها. الكلمات المفتاحية: المصرف المركزي، المصرف الإسلامي، المُسْعِف الأخير.

\section{Last Resort and Surplus liquidity in Islamic Banks}

\begin{abstract}
The purpose of this paper is to discuss and highlight the problems that have been facing Islamic banks as a result of the absence of last resort. While central banks in traditional financial systems act as the last resort for commercial banks and other financial institutions, Islamic banks suffer from the absence of last resort services according to the principle of shari'ah. If establishing Islamic last resorts is difficult for the time being, the researcher explores other alternatives, e.g., special windows in central banks to work as a last resort for Islamic banks which should comply with shari'ah principles. The difference between traditional financial institutions and Islamic financial institutions, concerning these issues will continue to raise difficulties and to present the priority of certain alternatives over others.
\end{abstract}

Keywords: Central Bank, Islamic Bank, last resort.

$$
\text { * دكتوراه في العلوم المالية والمصرفية الإسلامية، أستاذ مشارك في جامعة عمّان العربية، قسم التمويل والمصارف. البريد }
$$




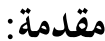

تتّسم العلاقة بين المصارف المركزية والمصارف الإسلامية بعدم الوضوح أولاً، وبتعدّد

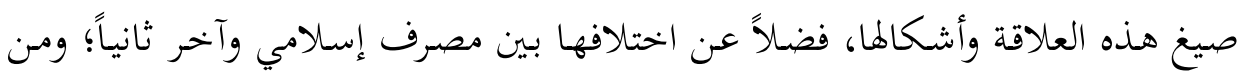

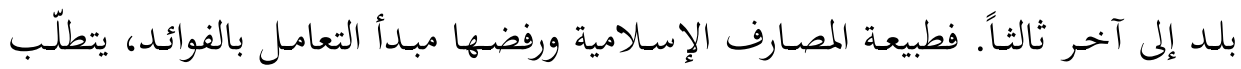

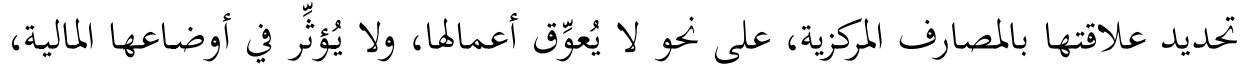

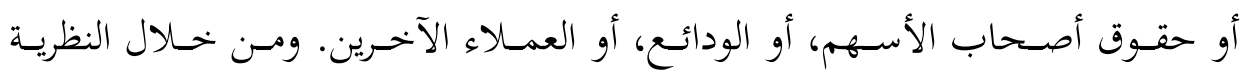

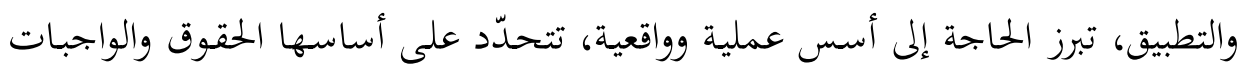

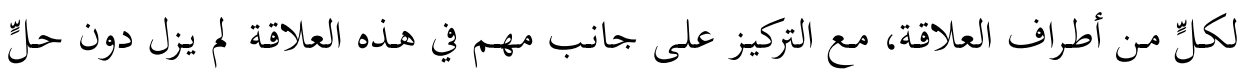

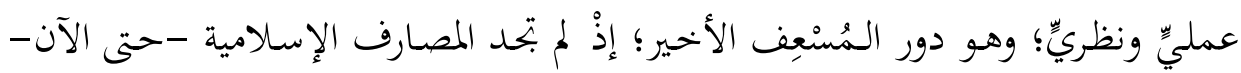

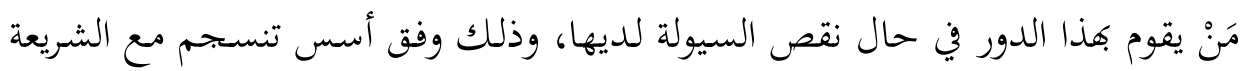

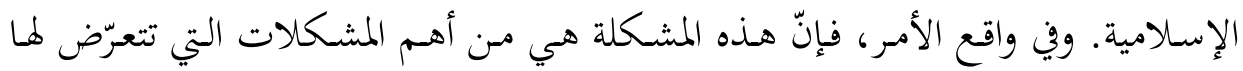

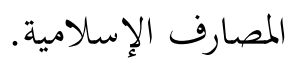

تستمد هذه الدراسة أهيتها من إيمان الباحثة، وإدراكها حاجة المصارف الإسلامية

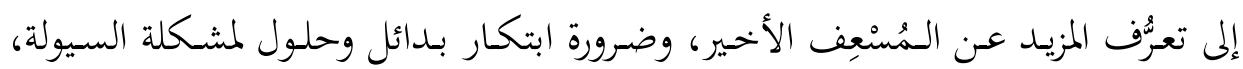

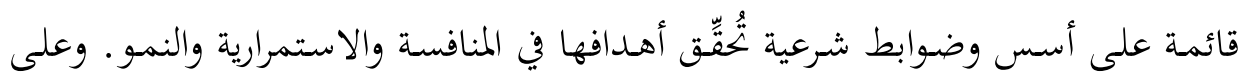

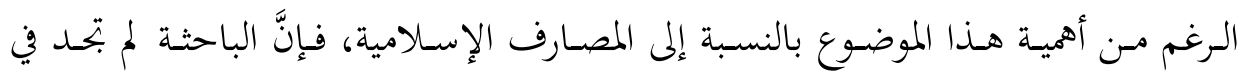

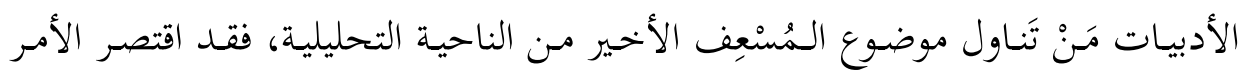

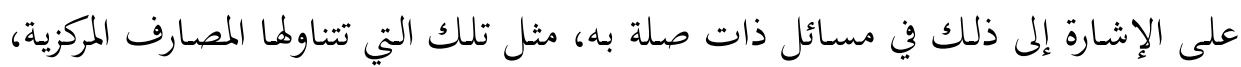

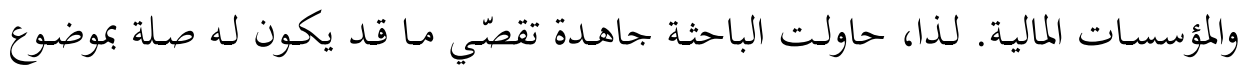
البحث ومجعه من كتب ومقالات وأبحاث ورسائل جامعية.

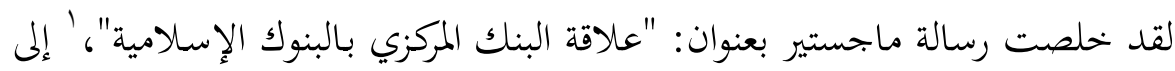

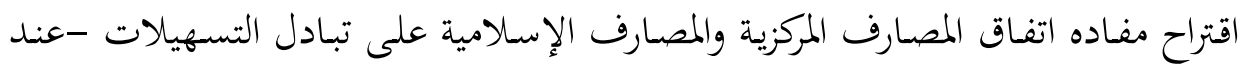

'العمايدة، محمد عودة. "علاقة البنك المركزي بالبنوك الإسلامية"، رسالة ماجستير في الاقتصاد الإسلامي، جامعة 
الحاجـة- على أسـاس المشـاركة في الأربـاح والخســائر. واقترحـت رسـالة دكتـوراه بعنـوان:

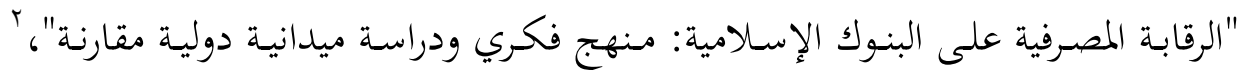

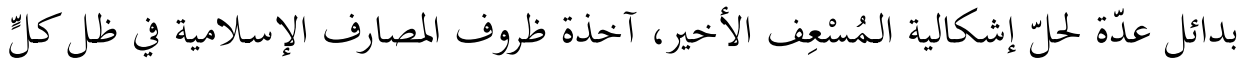

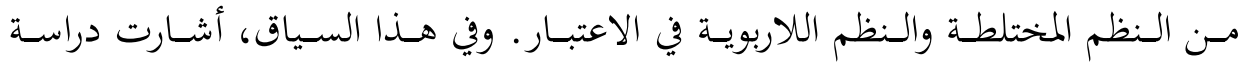

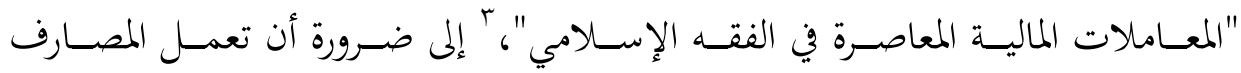
الإسلامية على إيجاد مصرف مركزي إسلامي عالمي للاقتراض منه من غير فائدة. في حين إلى مإن

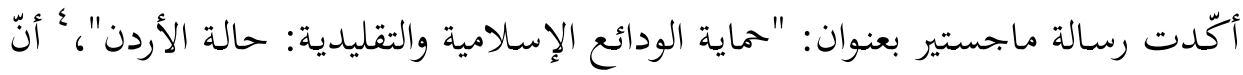

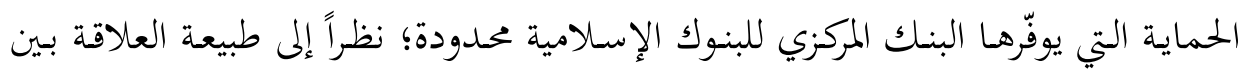

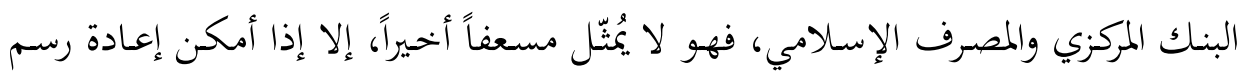

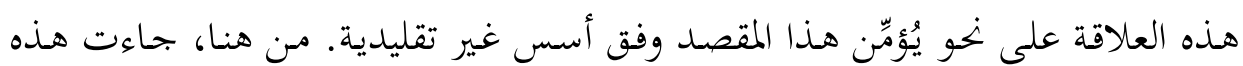

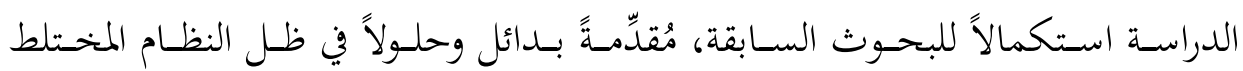
لإشكالية المُسنعِف الأخير في المصارف الإسلامية.

\section{أولاً: إنكالية المصارف الإسلامية ما بين المُسنِْف الأخير وفائض السيولة}

يقوم المصرف المركزي عادة بتوفير الدعم المالي للمصارف التقليدية وبعض المؤسسات المالية، ولا يقتصر ذلك على تمويل حالات العجز المفاجئ في السيولة، بل يمتد ليشمل توفير الموارد المالية التي تتيح لهذه المصارف تمويل بعض القطاعات التي تخظى بأهمية خاصة بلهي

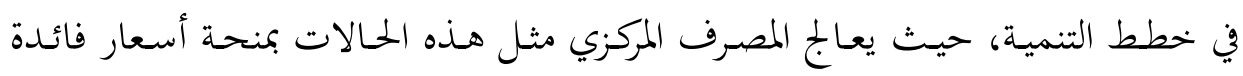

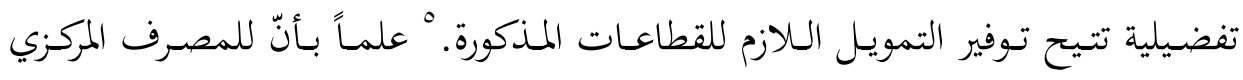
ץ ناصر، الغريب محمود. "الرقابة المصرفية على البنوك الإسلامية"، رسالة دكتوراه في إدارة الأعمال، جامعة عين

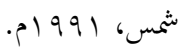

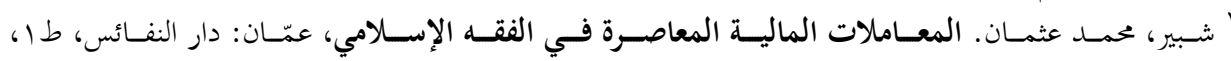
1997/ه1 1917 " الخلايلة، جاد الله محمد، "حماية الودائع الإسلامية والتقليدية: حالة الأردن"، رسالة ماجستير، جامعة اليرموك،

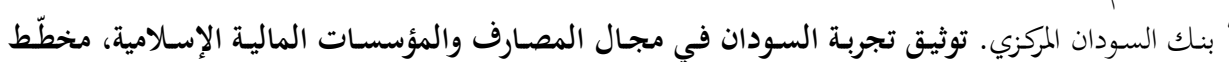

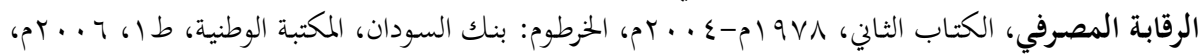


وسـائله في تقــيم السـيولة التي قـد تحتـاج إليهـا هـذه المصـارف؛ كخصـم الكمبيـالات،

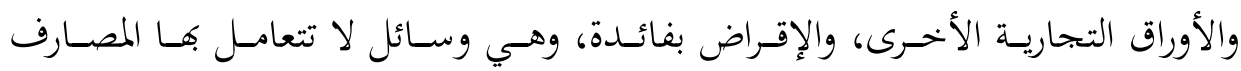

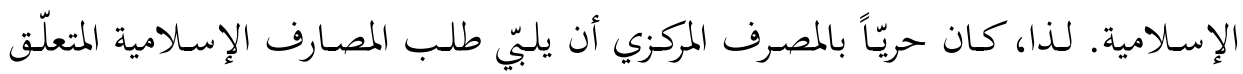

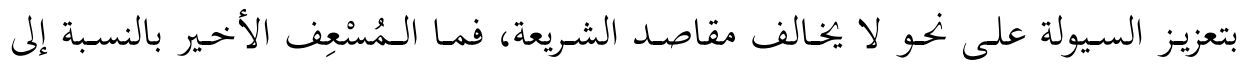
المصارف الإسلامية؟

يمتلك المصرف المركزي الوسائل والأدوات الفنيـة اللازمهة التي تتيح له تعرُّف حاجـة

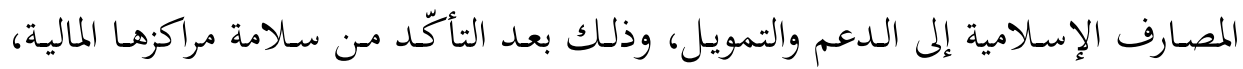

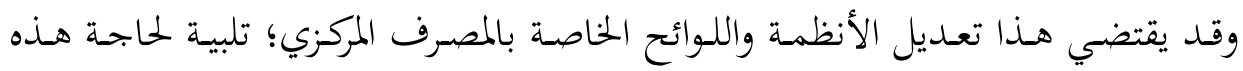

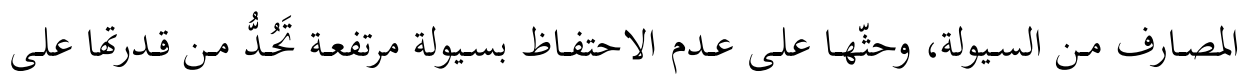
استغلال مواردها بصورة أفضل. وعليه، فقد أصبح لِزاماً وضع الأسس والقواعد والمعايير التي تضبط عملية لجووء المصارف الإسلامية إلى المصرف المركزي.

وتأسيساً على ما سبق، تقترح الباحثةُ تعريف المُسعِفَ الأخيرَ للمصارف الإسلامية

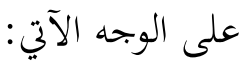

"المسعف الأخير للمصارف الإسلامية يعني: توفير البنك المركزي قروضاً للمصارف

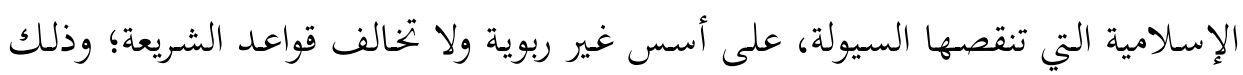

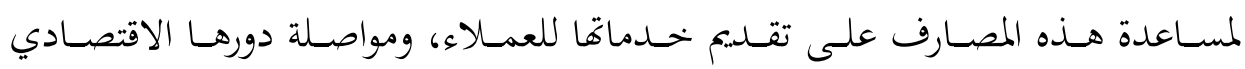
والاجتماعي. "

وقد أظهرت التجارب السـابقة تـدّّل مصـارف الدول المركزية في أعمال المصـارف

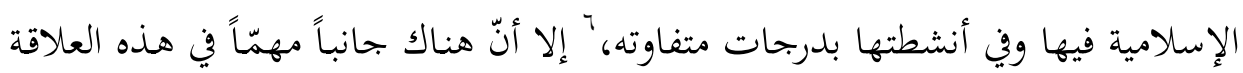

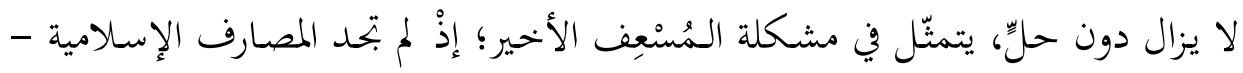

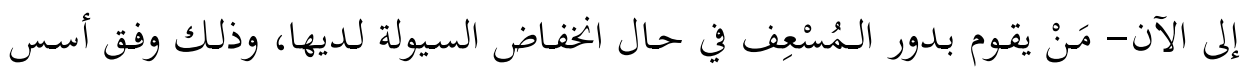

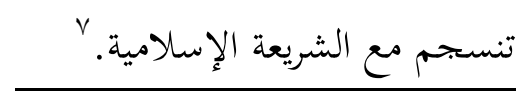

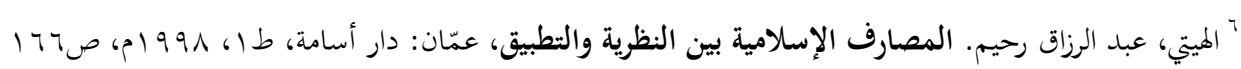


وفي الوقت الذي تتلقّى فيه المصارف التجارية التقليدية دعماً من المصرف المركزي، يُوََمَُُّ لها السيولة التي قد تحتاج إليها، تواجه المصارف الإسلامية مشكلة بهذا الخصوص،

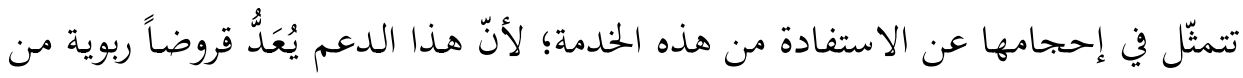

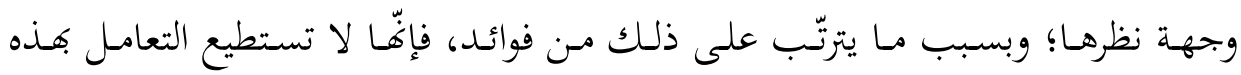

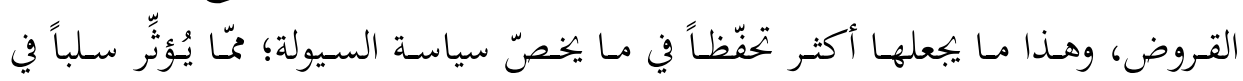

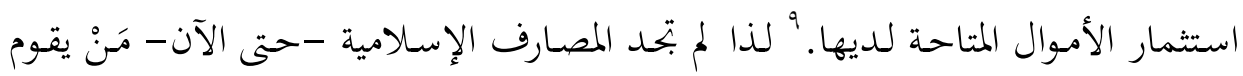

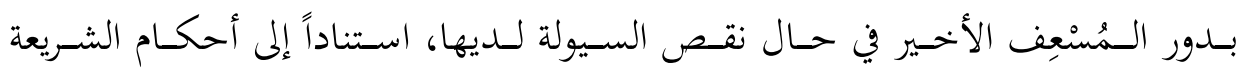

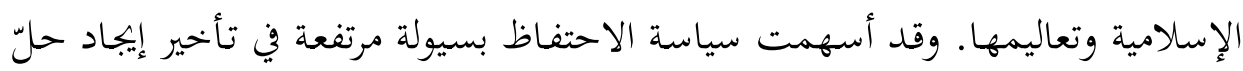

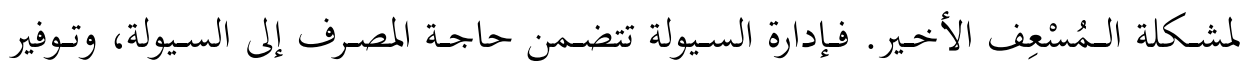

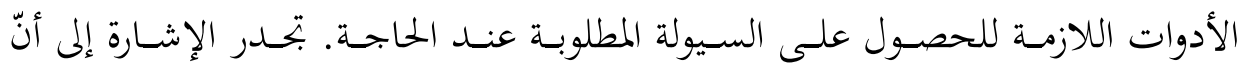

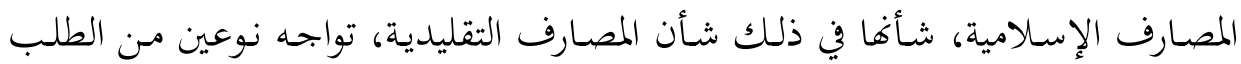
على السيولة، هما: '

1. توفير السيولة اللازمة التي تتيح للعملاء السحب من ودائعهم.

r. الاحتفاظ بسيولة كافية تلبّي حاجة العملاء من التمويل، ورغبتهم في الاستثمار. وعليه، فنسب السيولة تقيس أخطار عدم القدرة على تلبية النوعين المذكورين أعلاه

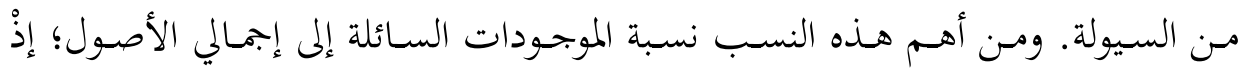

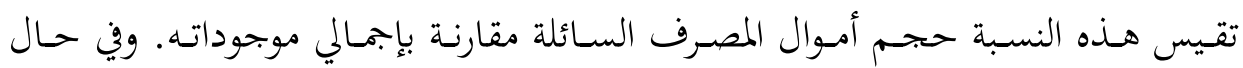

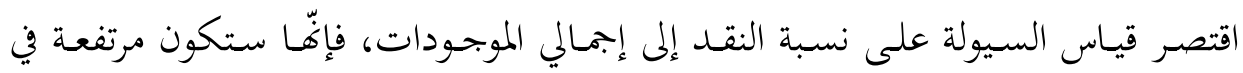
المصارف الإسلامية، ويمكن قياسها حسب المعادلة الآتية:

$$
\text { النقد وأرصدة المصرف المركزي والمصارف الأخرى }
$$

بحموع الموجودات

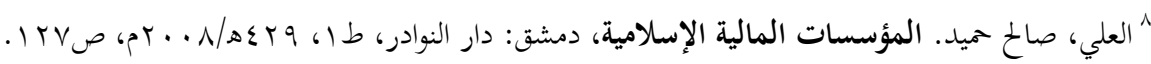

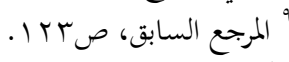

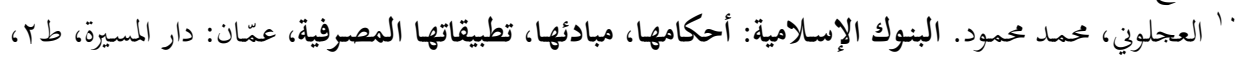


وبتطبيق المعادلة السابقة على بيانات المصرف الإسلامي الأردني للأعوام (7 . . بام-

• · • ا م)، يبيّن الجحدول الآتي نسبة الموجودات السائلة إلى إجمالي الأصول:

\begin{tabular}{|c|c|c|c|c|c|}
\hline$r \cdot 1$. & $r \ldots q$ & $r \cdots \wedge$ & $r \cdots V$ & $r \ldots T$ & السنة \\
\hline$\% \leq r$ & $\% \varepsilon$. & $\% r v$ & $\%$ & $\%$ rv & نسبة الموجودات السائلة إلى إجمالي \\
\hline
\end{tabular}

المصدر: قامت الباحثة باستخراج هذه النسب من التقارير السنوية للبنك للسنوات المشار إليها.

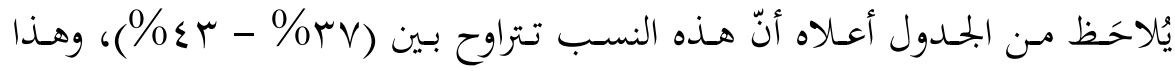

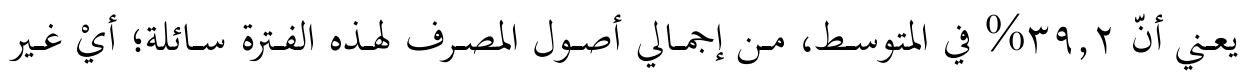

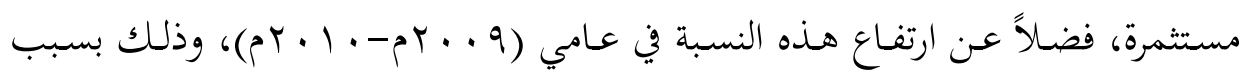

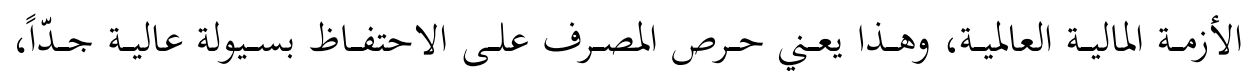

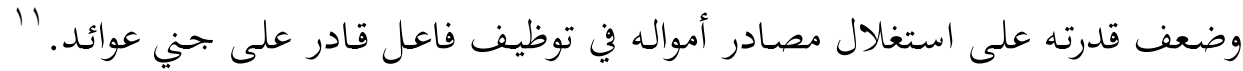
علماً بأنّ المصارف الإسلامية تحرص عند استثمار الأموال المودعة لديها على تجميد قسم فئم منها؛ للحفاظ على درجة معقولة من السيولة تقيها أخطار السحب المفاجئ للمودعين. بحدر الإشارة إلى تعرّض مصرفين فقط لمشكلة انخفاض السيولة، هما: بيت التمويل

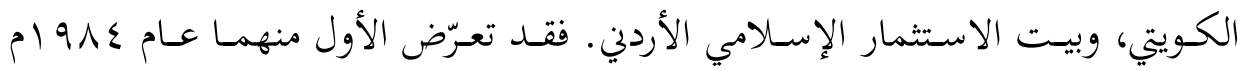

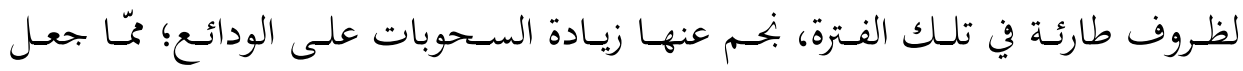

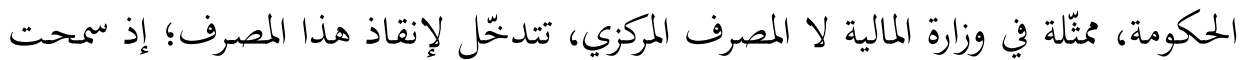

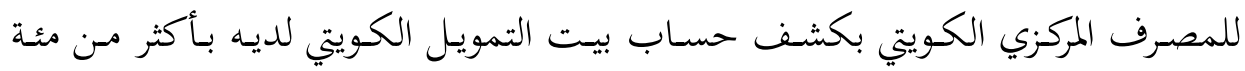
مليون دينار كويتي، وقد جاء هذا التدخّل من الحكومة نتيجة لإسهامها في هذا المصرف،

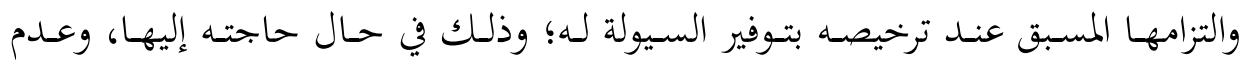

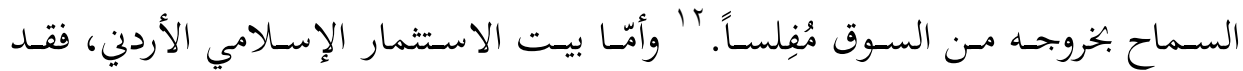

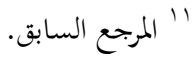
r' الحزيم، يوسف بن عثمان. لمان. تحوّل المصرف المركزي التقليدي إلى مصرف مركزي إسلامي، الرياض: مكتبة دار

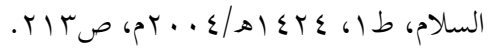




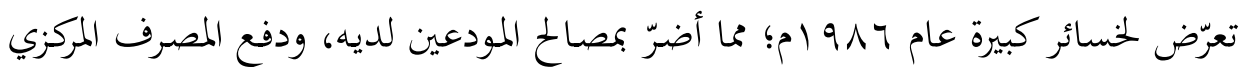

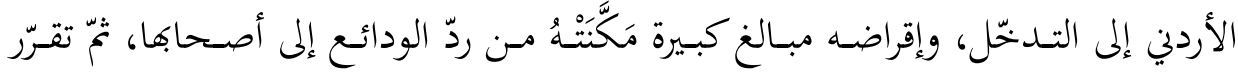

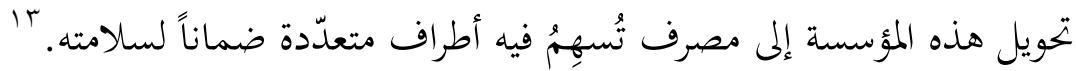

ثانياً: الآثار السلبية الناتجة من وجود فائض أو نقص في السيولة لدى المصارف الإسلامية

إنّ الأسـس والقـوانين التي تحكـم العمـل في المصـارف الإسـلامية لا تسـمحح لهـا أن تتصرّف بفائض السيولة مثلما تصنع المصارف التقليدية التي تتعامل بنظام الفائدة الربوية؛

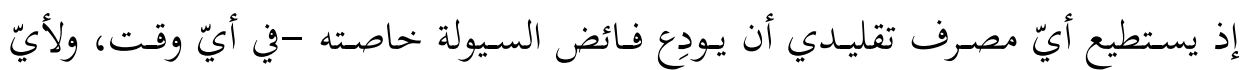

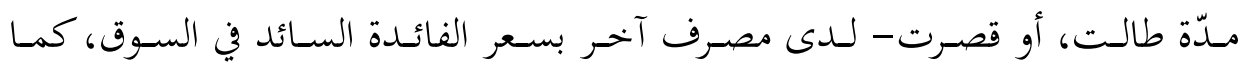
يستطيع في حـال العجز الاقتراضَ من أيّ بنـك تقليدي آخحر، أو من المصرف بــ المركزي.

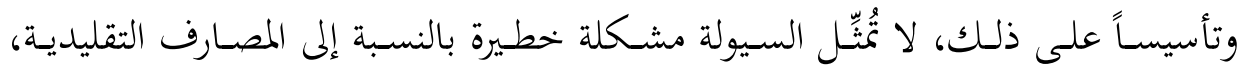

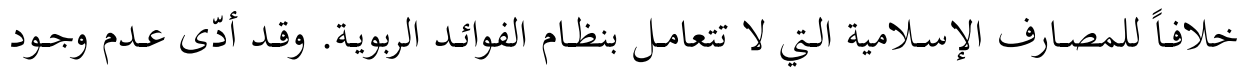

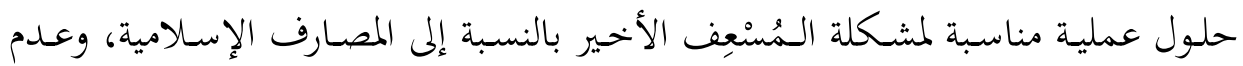

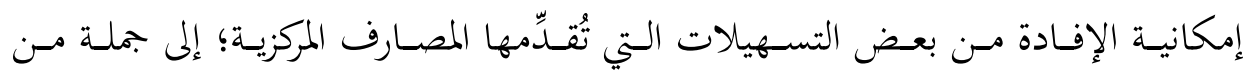
السـلبيات التي أتثرّت في أداء المصـارف الإسـلامية. وعليـه، يمكـن تحديــ الآثـار السـلبية

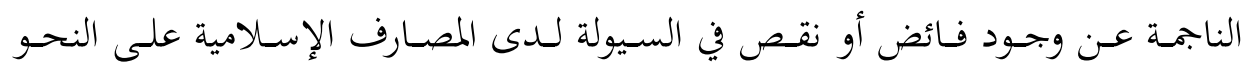
الآتي: ع

\section{ا ـ الآثار السلبية الناتجة من فائض السيولة في المصارف الإسلامية:}

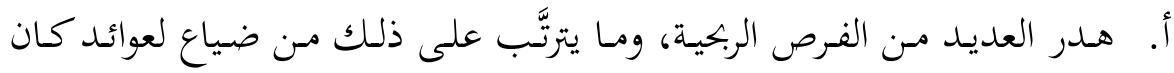

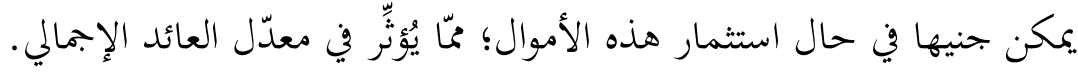
"الميسن، عبد الحليم إبراهيم. "تقييم تجربة البنوك الإسلامية"، رسالة ماجستير مقدمة إلى كلية الاقتصاد، الجامعة

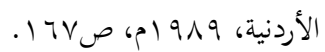

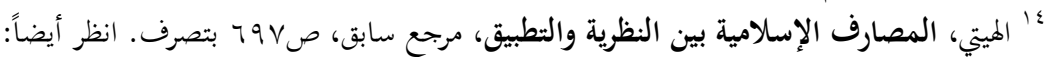

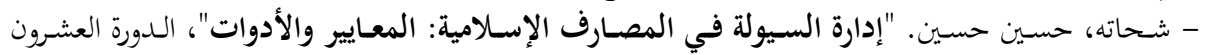

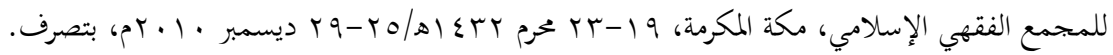


ب. تأتّرّ الفائض من الأموال بالتضخّم النقدي بسبب انخفاض القوّة الشرائية للنقد؛ مُّا يُؤثبّر في معدّل الربح، والقيمة الحقيقية لرأس المال. ت. الإيحاء بعدم كفاءة إدارة النقد في هذه المصارف؛ بدعوى عدم قدرة إداراتها على

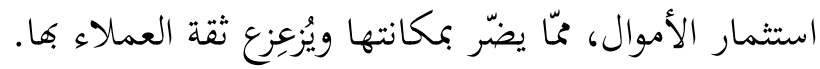
ث. مخالفة أحكام الشريعة الإسلامية وتعاليمها السمحة، التي تُحرِّم بحميد الأموال، وعدم استثمارها في المشروعات المتعدّدة.

ج. لجوء معظم المصارف الإسلامية إلى توجيه استثماراتما إلى المرابحة لضمان التدفّق النقدي والعائد عليها؛ ممّا يجعل مدّة التمويل والاستثمار لديها قصيرة الأجل. ح. عـدم الإسـهام في تمويل المشروعات الإنتاجيـة؛ مُّا يـؤدي إلى زيـادة وطأة الفقـر والبطالة.

\section{Y. الآثار السلبية الناتجة من نقص السيولة في المصارف الإسلامية: أ. حدوث خلل في تمويل المشروعات الاستثمارية.}

ب. الاعتمــاد علـى اسـتمرارية تــفّق الودائـع في بنـاء الخطــط والاسـتراتيجيات الاستثمارية.

ت. تعذُّر بناء خطط استثمارية طويلة الأجل اعتماداً على تدفّق الودائع؛ نظراً إلى ألى

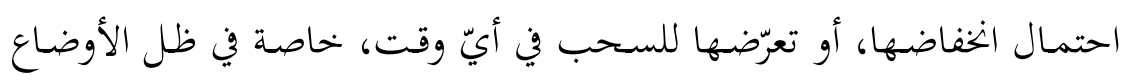
الاقتصادية غير المستقرة. ث. عـدم قـدرة هـذه المصـارف على استغلال مواردهـا على النحـو الأمثل؛ مُّا يُعَدُّ

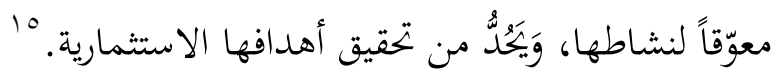

ج. عدم مقدرة هذه المصارف على سداد الالتزامات بحاه الآخرين في مواعيدها؛ مّّا يضرّ بمكانة المصرف الإسلامي. 


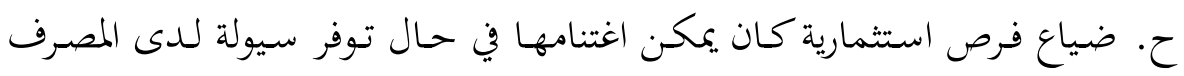
الإسلامي، ولا سيّما المشروعات الاستثمارية.

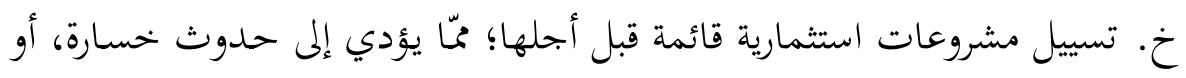

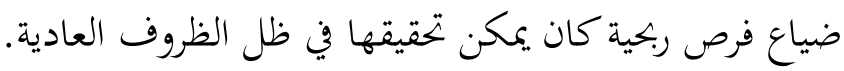

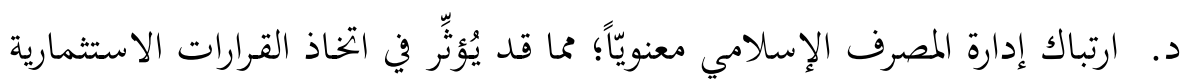

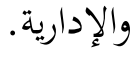

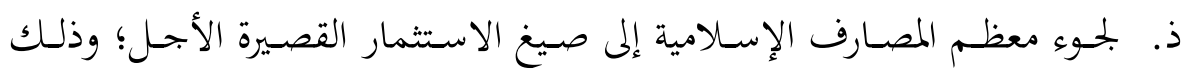
بسبب احتمال تحافت العملاء على سحب ودائعهم في أيّ وقت.

ثالثاً: البدائل والحلول المقترحة لمشكلة المُسْعِف الأخير للمصارف الإسلامية

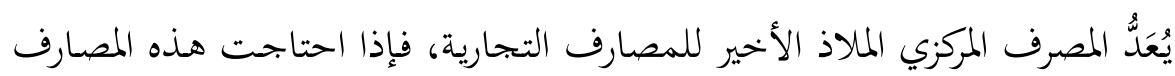

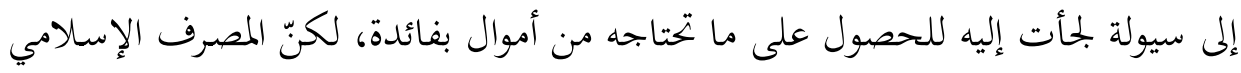

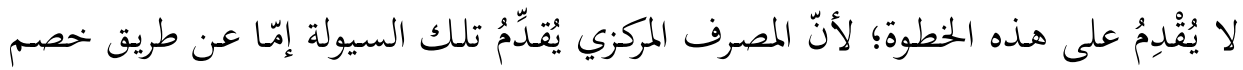

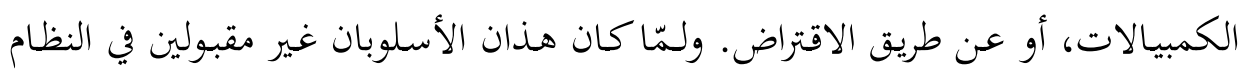

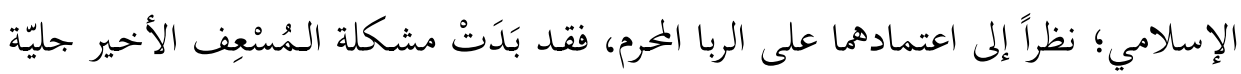

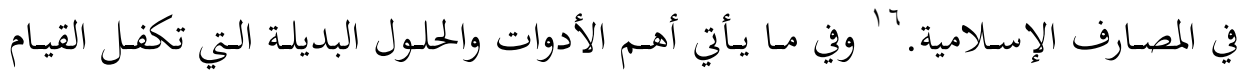

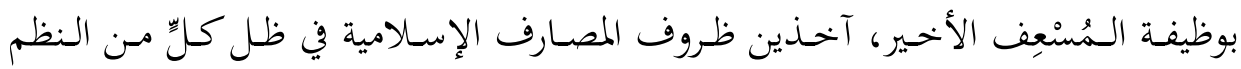
المختلطة أو النظم اللاربوية، والخصائص المميزة للعمل المصريف الإسلامي في الاعتبار: ا ـ تطوير سوق مالية إسلامية، وأدوات ائتمانية تتفق وأحكام الشريعة الإسلامية؛

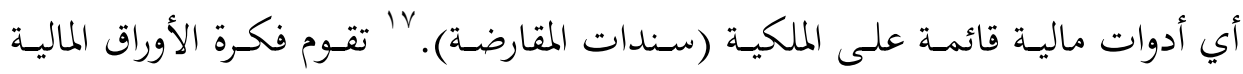

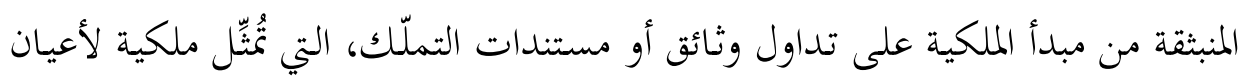

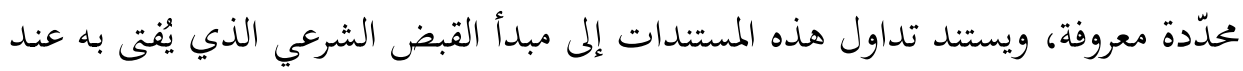

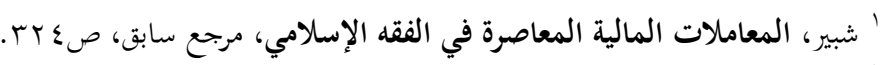

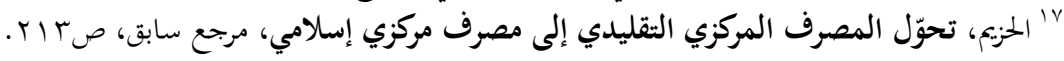




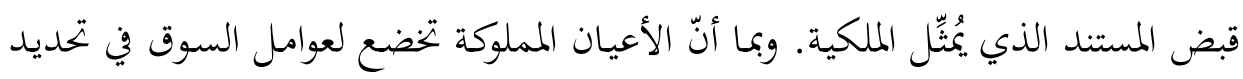

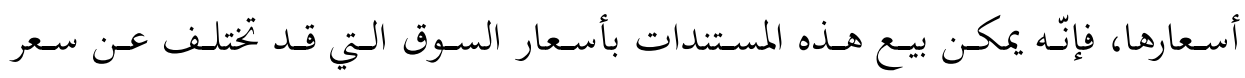

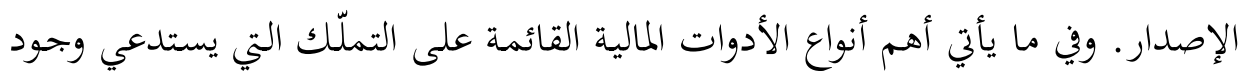

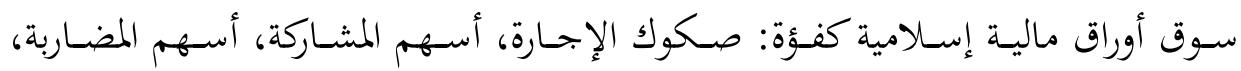

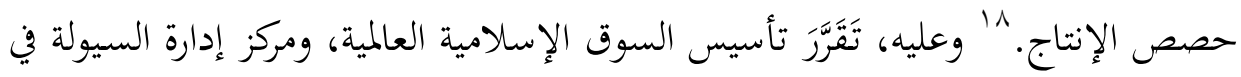

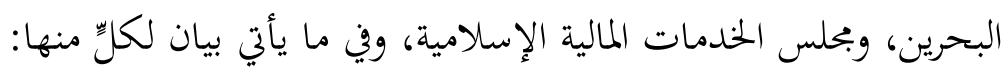

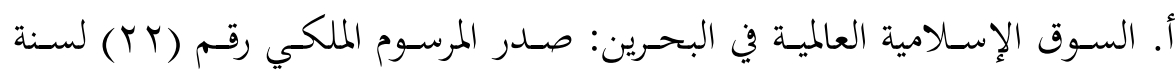

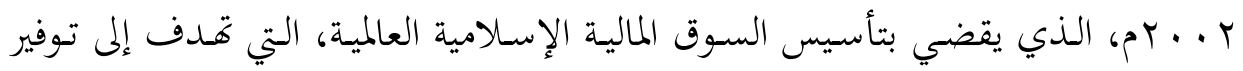

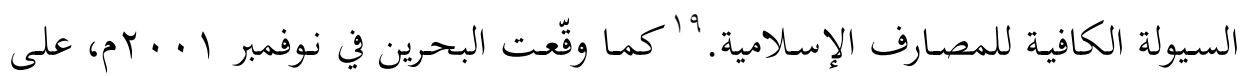

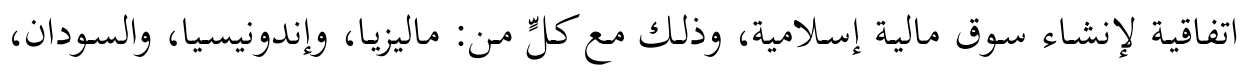

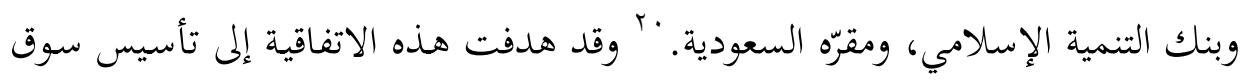

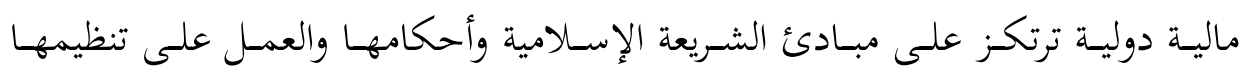

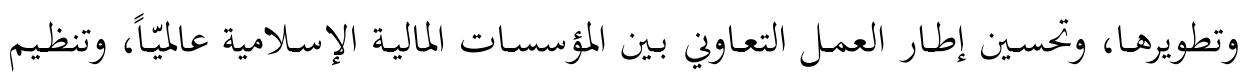

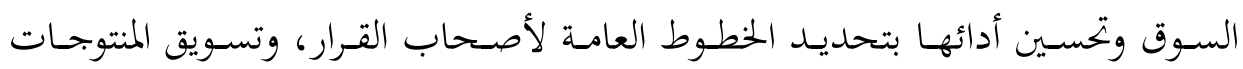

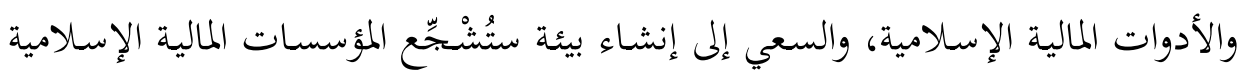

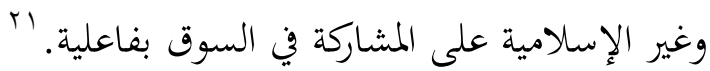

ب. مركـز إدارة السـيولة في البحــين: تأسّس مركـز إدارة السـيولة في يوليـو عـام

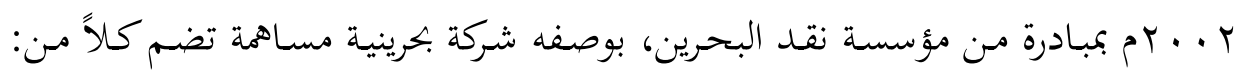

^' قحف، منذر. . السياسـة المالية ودورهـا وضسوابطها الإسـلامية، بيروت: دار الفكر المعاصر، ط1، 991 (م)، صזr.

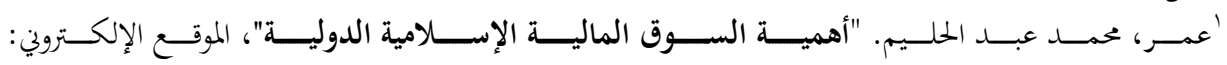

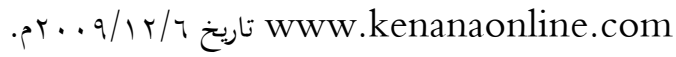

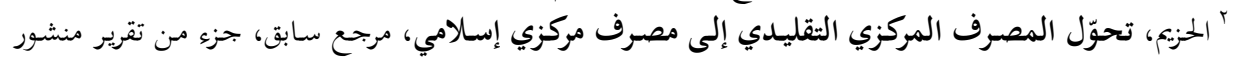

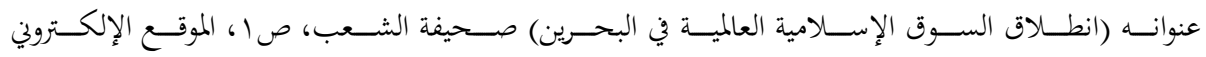

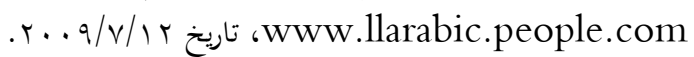

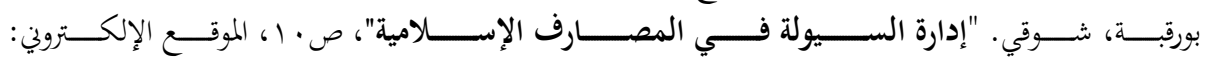

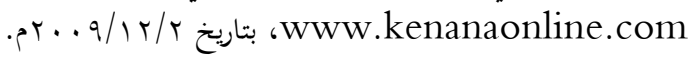


بنك البحرين الإسلامي، وبنك دبي الإسلامي، والبنك الإسلامي للتنمية، وبيت التمويل

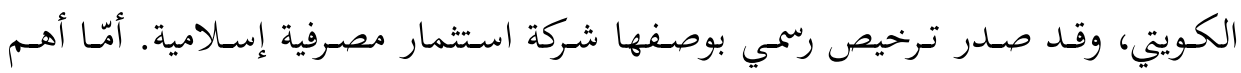

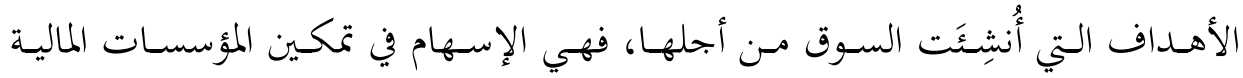

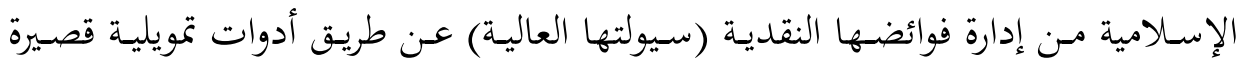

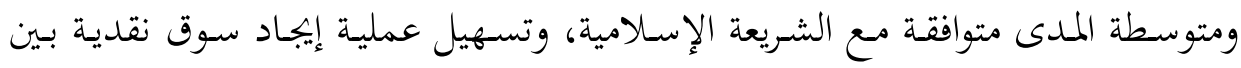

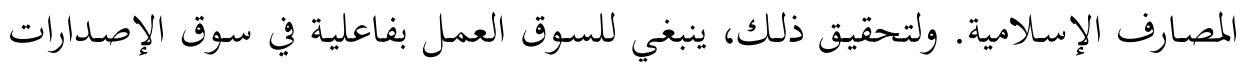

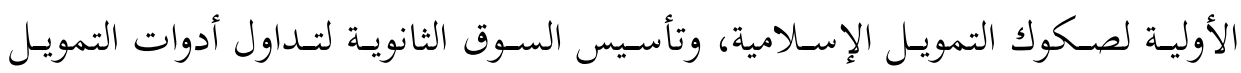

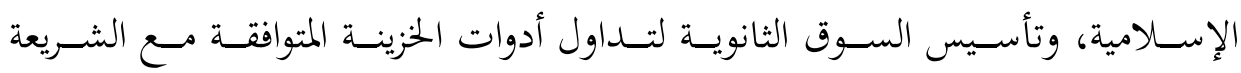

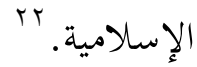

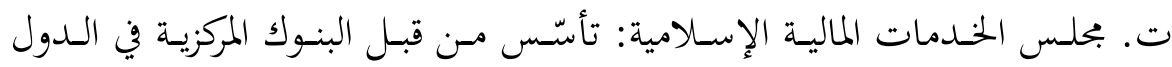

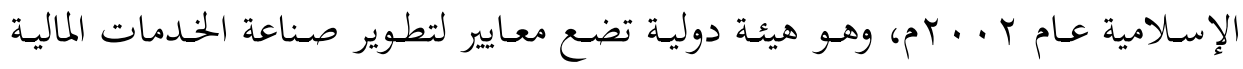

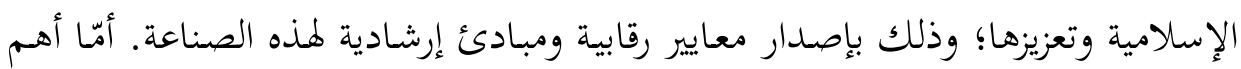

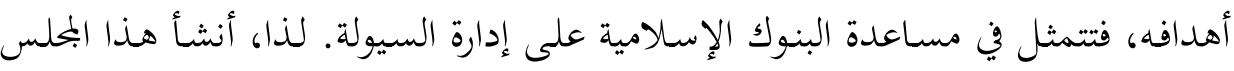

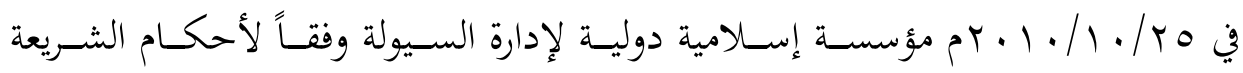

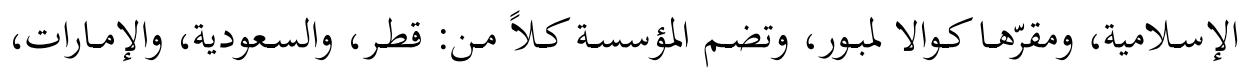

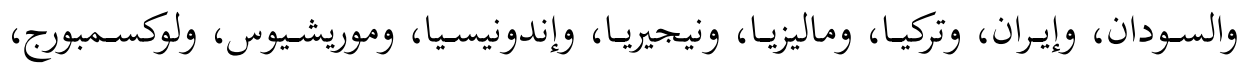

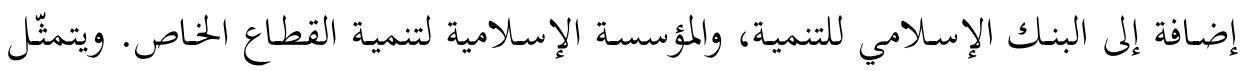

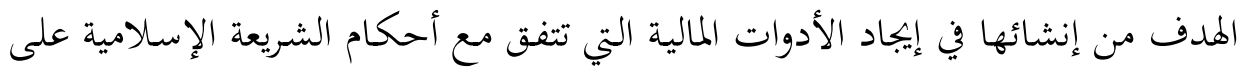

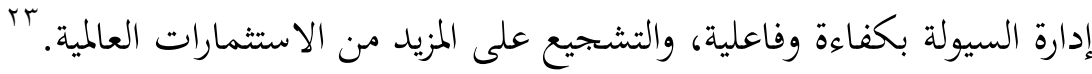

r. إيبـاد آلية للتعاون بين المصـارف الإسـلامية؛ بهـدف الاتفـاق على مـا يُسمّمى فئس

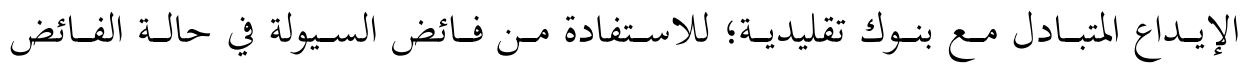

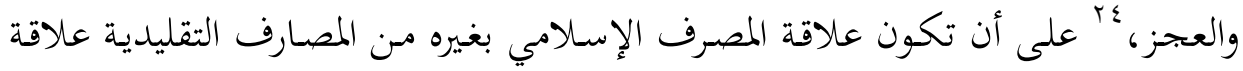

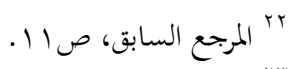

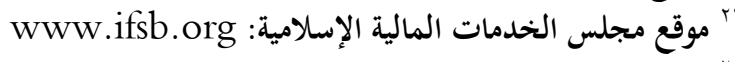

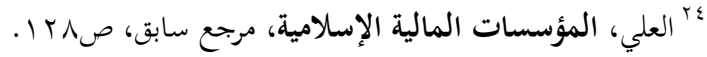




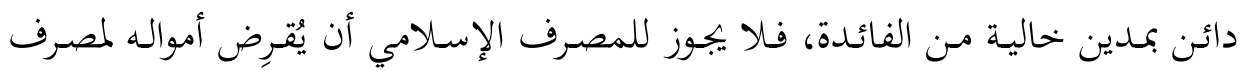

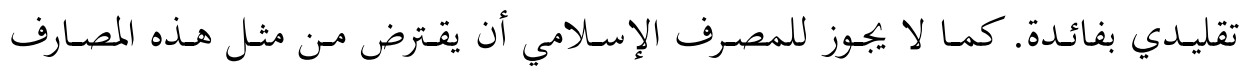

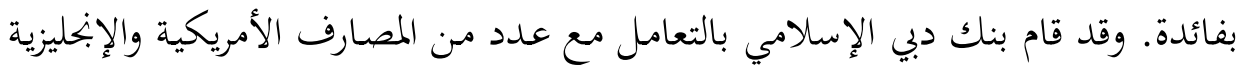
والسويسرية على أساس غير ربوي، وتقديم الخحدمات المصرفية مُبرَّة من الفوائد.

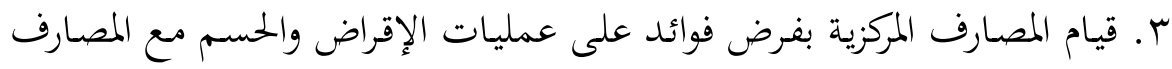

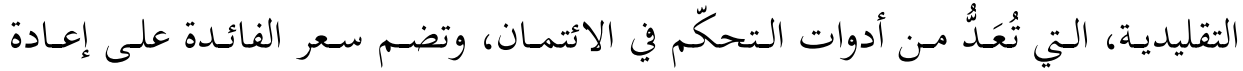

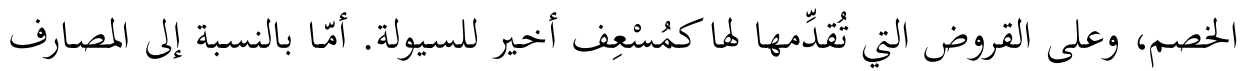

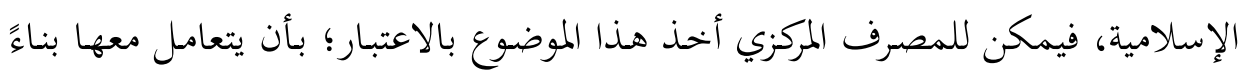

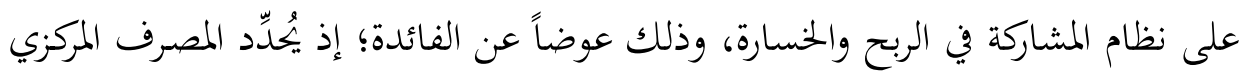

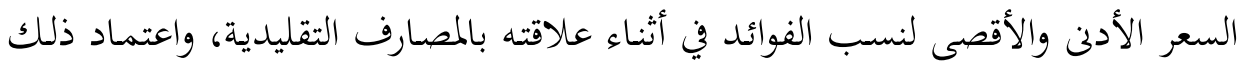

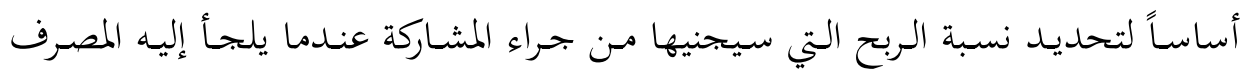

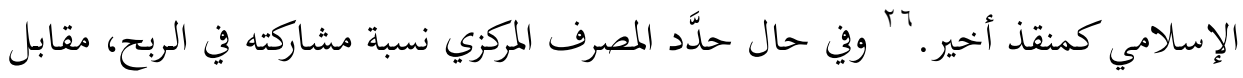

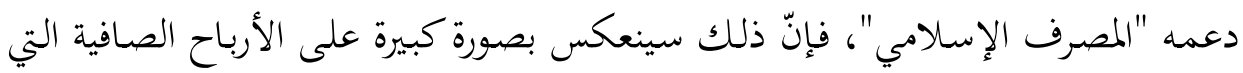

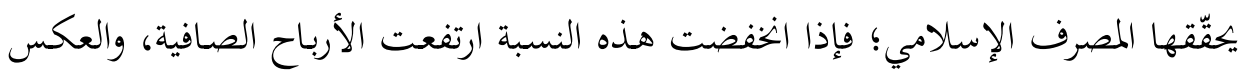

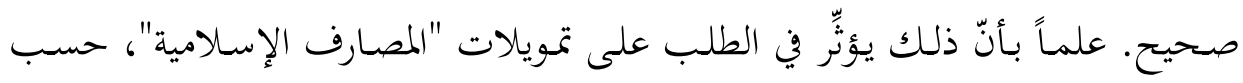

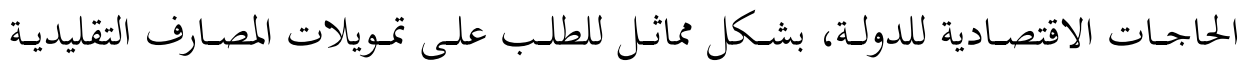

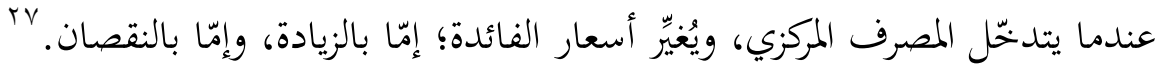

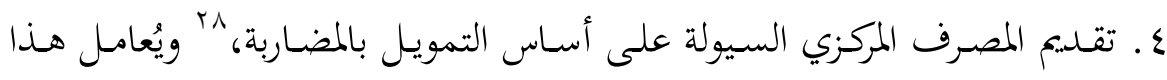

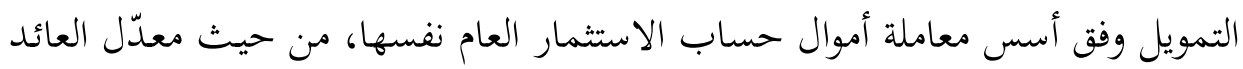

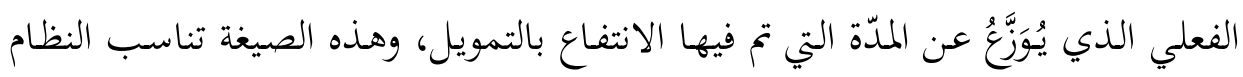

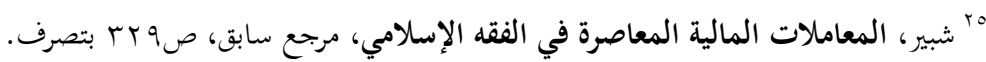

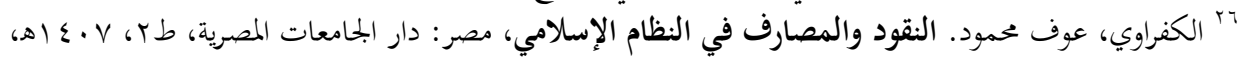

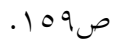
rv المالقي، عائشة الشرقاوي. البنوك الإسلامية: التجربة بين الفقه والقانون والتطبيق، الدار البيضاء: المركز الثقافي 
المختلط. كما تناسب -من باب أولى - النظام الإسلامي، إلا أنّه يجب أن يُراعى في كلتا

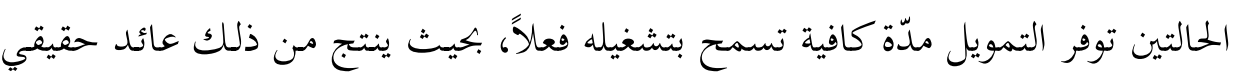

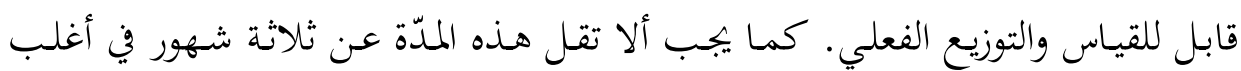

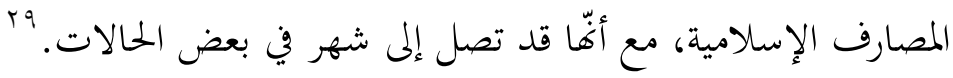

وعلى الرغم مـن أنّ تلك الصيغة قد تبدو غير متسقة مع منطق وظيفة الـمُسْعِف الأخير التي يمارسها المصرف المركزي، التي غالباً ما ترتبط بوضع شروط وترتيبات معينة تتعلّق بتنظيم الموقف المالي للمصرف طالب التمويل؛؛ وذلك بهدف تقوية مركز السيولة لديه، إلا أنّ ذلك لا يمنع من تطبيقها في إطار هذه الشروط والترتيبات التي يراها المصرف

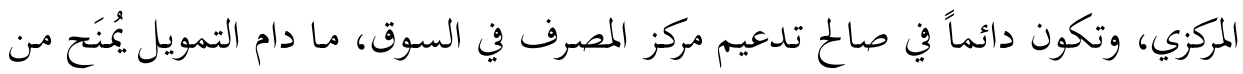

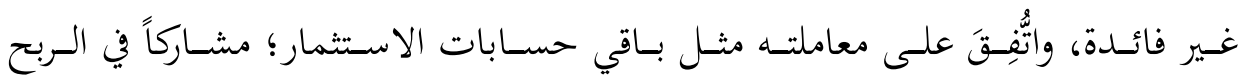

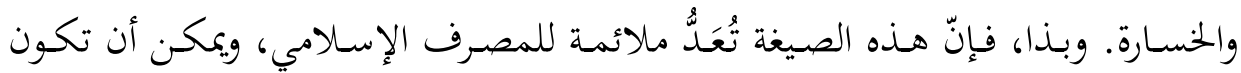
كذلك من وجهة نظر المصرف المركزي. ه. دخول المصرف المركزي، شريكاً بالتمويل مع البنك الإسـلامي، في عمليات أو

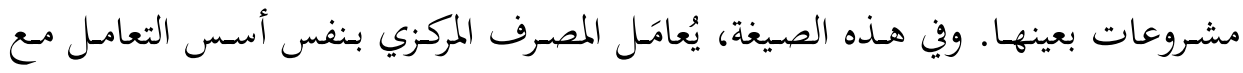

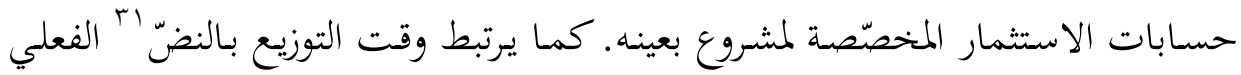
للمال في هذا المشروع، وبعملية استرداد التمويل المُقدَّم، التي يجب أن ترتبط بالتدفّقات

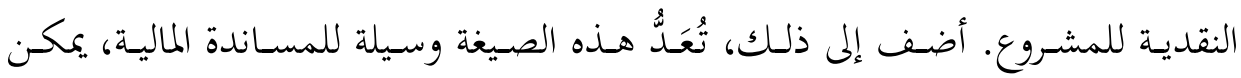
استخدامها لتشجيع المصارف على المشاركة في مشروعات تدعيم اقتصاد الدولة، فضالاً عن إتاحة المحال أمام المصارف الإسلامية لإيداع نسبة بسيطة من حسابات الاستثمار

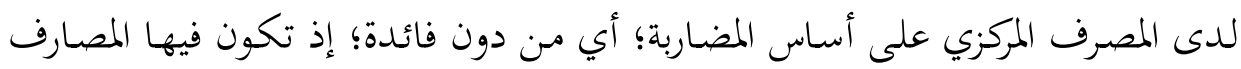
هي صـاحبة المـال، والمصـرف المركزي هـو المضـارب بعَمَلمِهِ. وفي حـال احتـاج مصـرف 


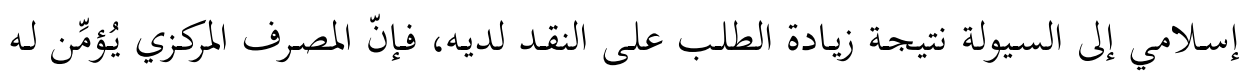

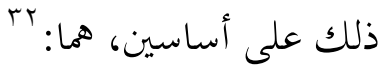

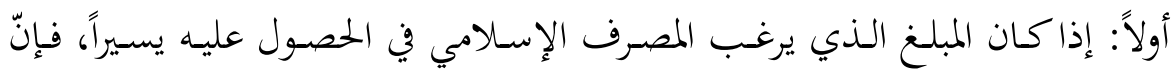

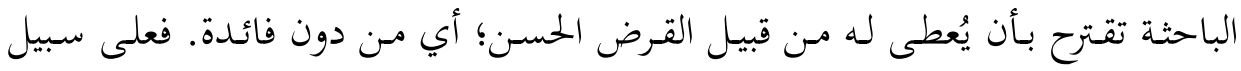

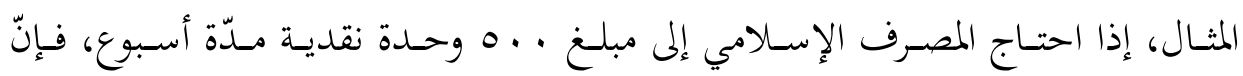

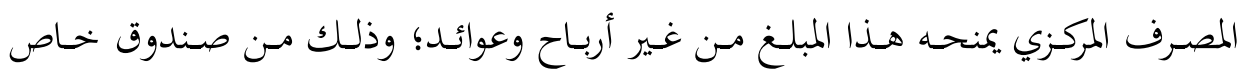
يؤسسه المصرف المركزي لهذا الغرض.

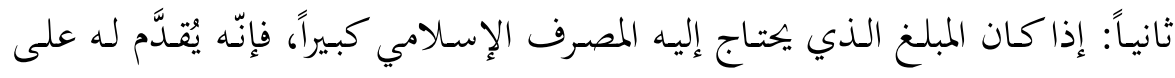

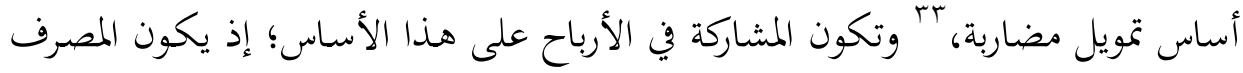

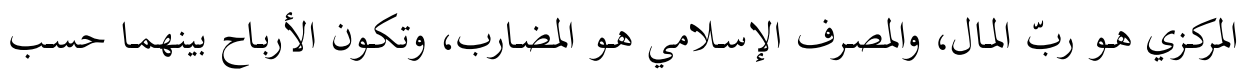

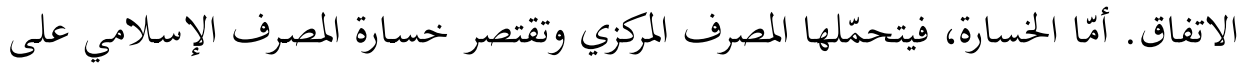
أعماله وأتعابه.

وبذلك، تكون هذه الصيغة أكثر تناسباً مع وضع النظم المصرفية الإسلامية؛ نظراً

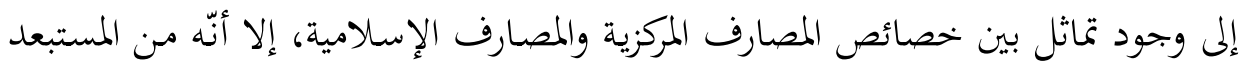

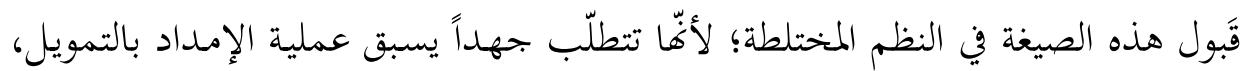

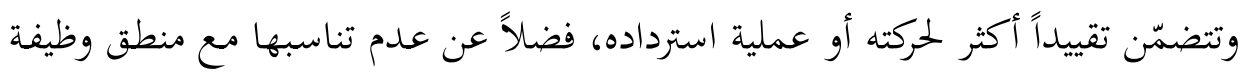
المُسْعِف الأخير من منظور المصرف المركزي.

وعلى الرغم من أنّ هذه المعاملة (المضاربة) تناسب المصارف الإسلامية وتساعدها

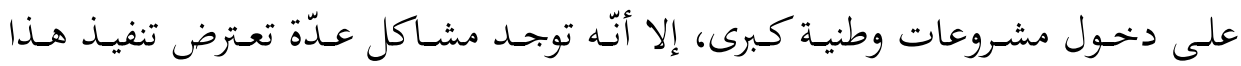

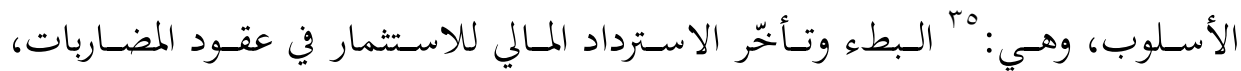

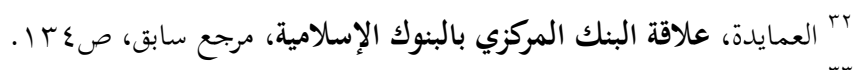

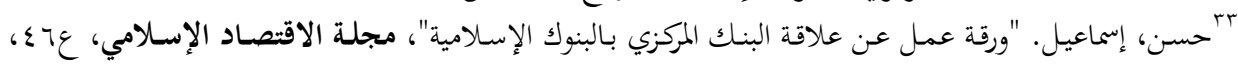

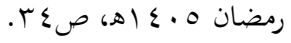

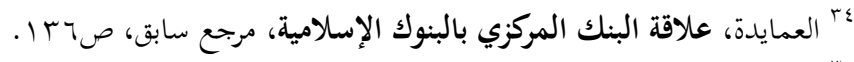

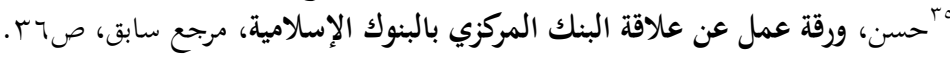




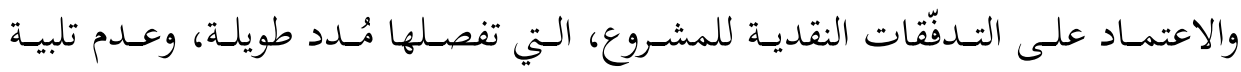

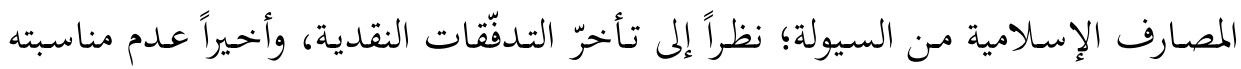

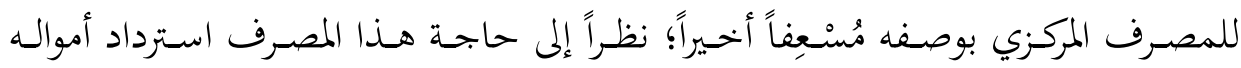

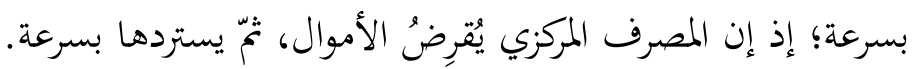

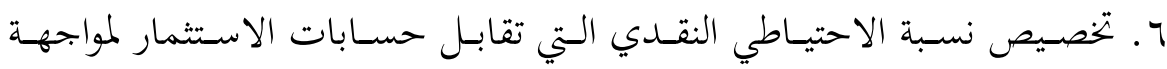

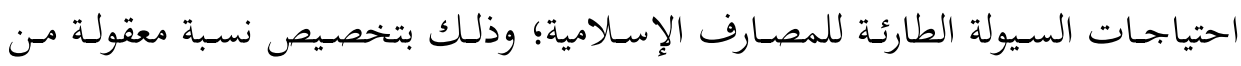

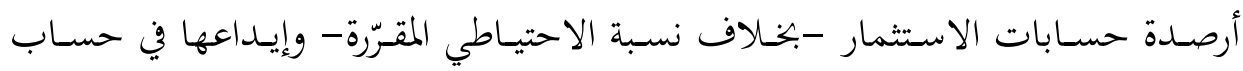

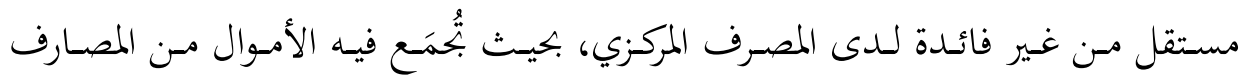

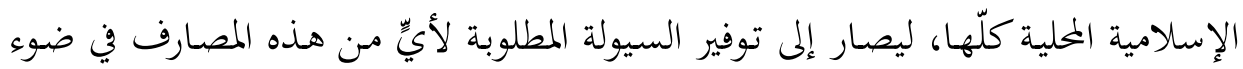

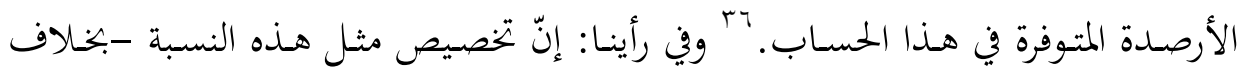
نسبة الاحتياطي النقدي السابق خصمها من حسابات الاستثمار - يُشَّلّ عبئًاً إضافياً

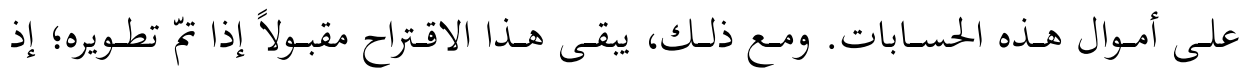

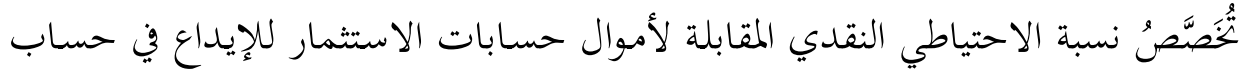

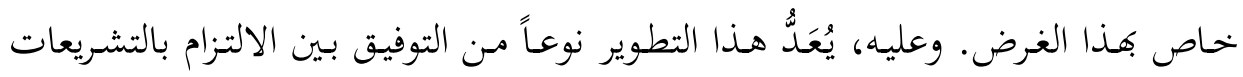

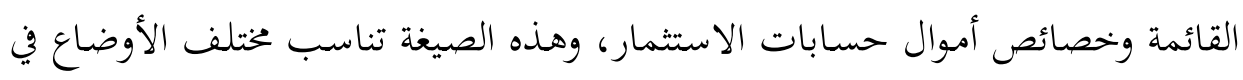

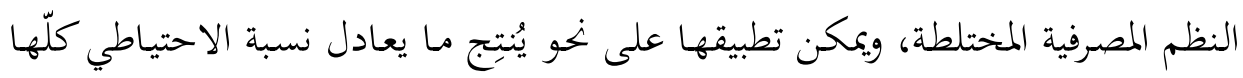

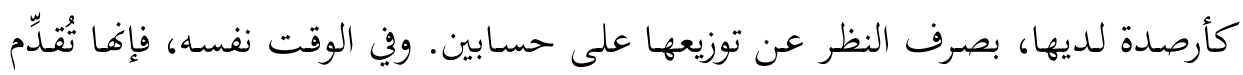

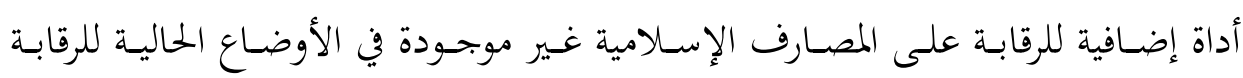
المصرفية.

V. إنشاء صندوق مشترك للسيولة يُسهِهُم فيه كل مصرف إسلامي بنسبة من أموال

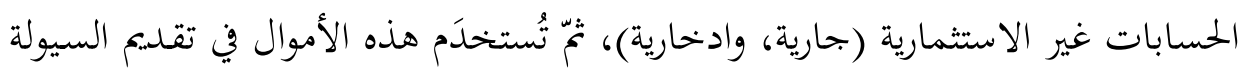

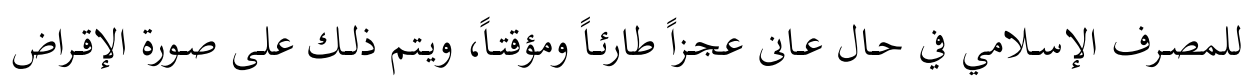

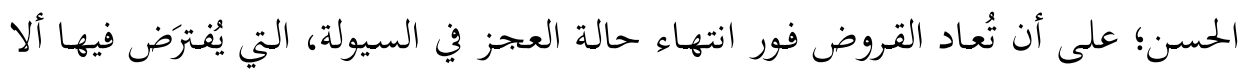

بَ" ناصر، الرقابة المصرفية على البنوك الإسلامية، مرجع سابق، صז 10 .

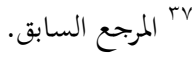




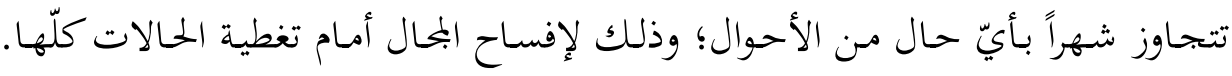

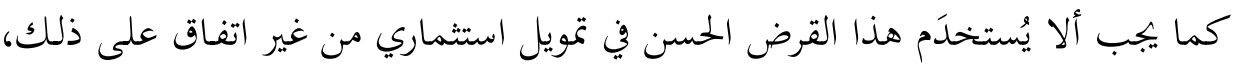

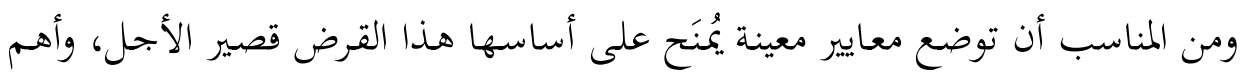

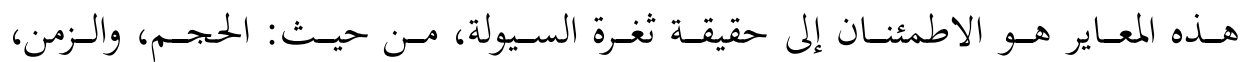

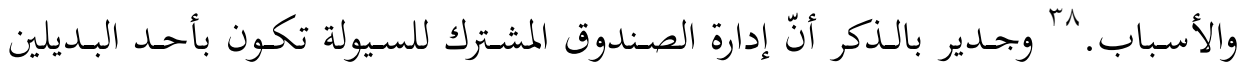

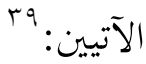

البديل الأول هو المصرف المركزي: وذلك في إطار لائحة متفق عليها، ويُفضَّل في

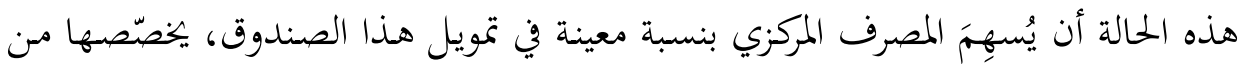
أرصدة نسبة الاحتياطي النقدي الخاصة بكل المصارف الإسلامية القائمة في الدولة.

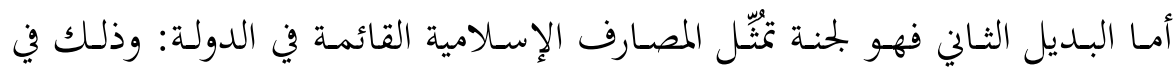

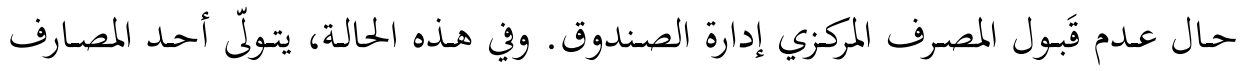

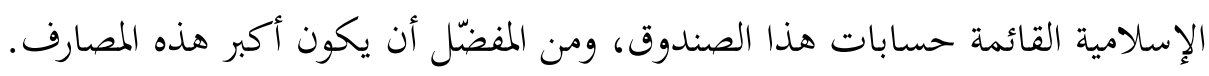

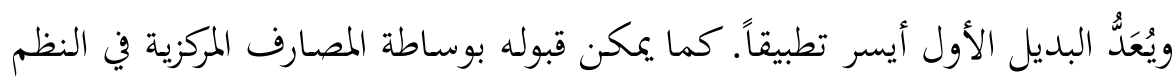

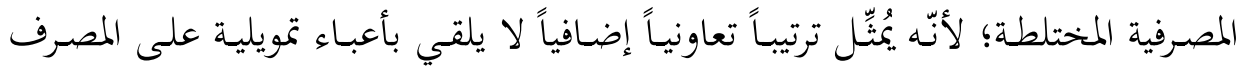

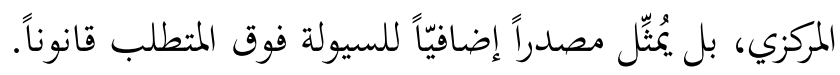

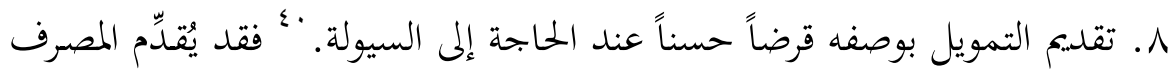

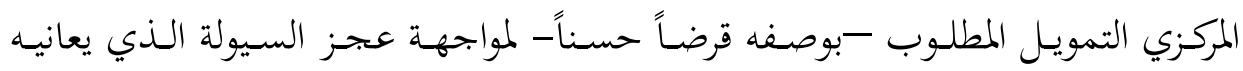

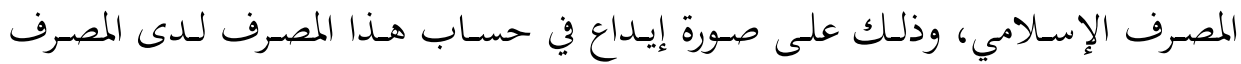

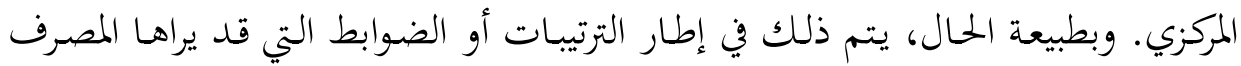

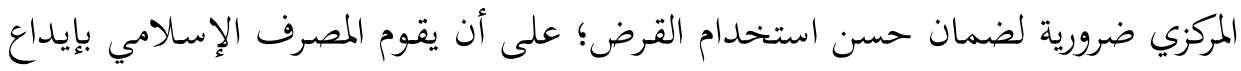

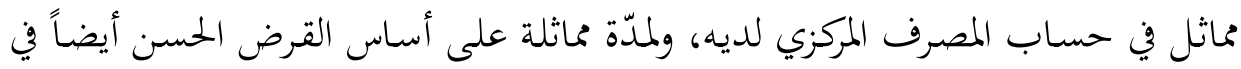

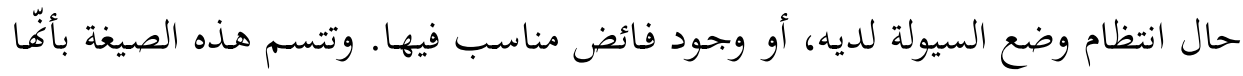

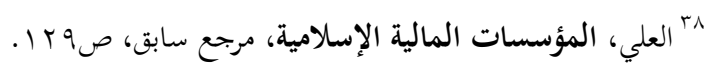

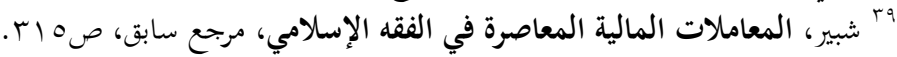

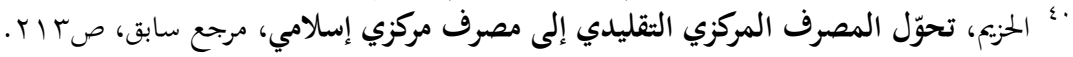


عملية قابلة للتطبيق في النظامين: المختلط، واللاربوي؛ وهي قريبة الشبه بنظام الإيداعات

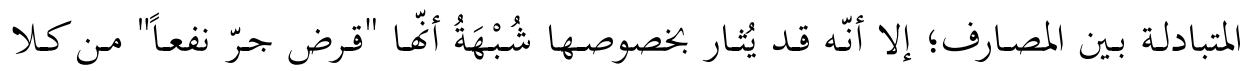
الطرفين؛ إذ لم يُمنَح القرض الأول إلا على أساس اشتراط منح القرض الثاني، فهل تدخل

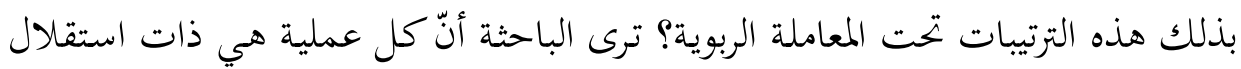

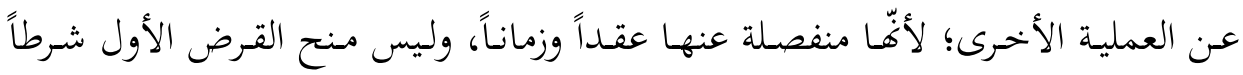
لحدوث القرض الثاني المقابل، بل قد يتم الأول، ومع ذلك لا تتحسيّن حالة السيولة، فلا

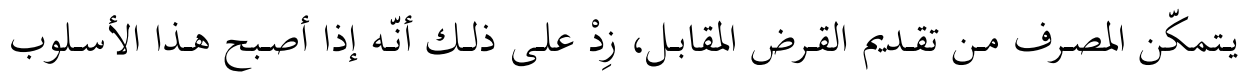
متبعاً مـن البنك المركزي، فسوف يكون مصدر منح القرض الأول من بين الموارد المتاحة

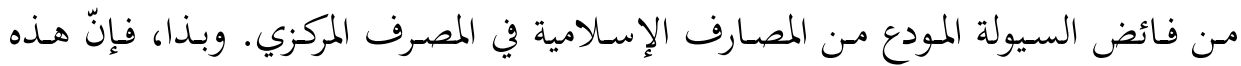
الصيغة تُعدُّ ملائمة، كما أفّّا ممكنة التطبيق. 9. ترتيـبـ إمــاد السـيولة بــن المصــارف الإســامية علـى المســتويين العـربي،

لا يُعَدُّ هذا المقترح بـديلاً عن المقترحات السـابقة، بل يتكامل معها ويُعزّزهـا، ويمتد القصــ منـه إلى تـوفير السـيولة بالعملـة الحـرّة القابلـة للتحويـل عنــدما يصـعب توفيرهـا للمصرف الإسلامي من السوق المحلية. وفيه تقوم المصارف الإسلامية بعقد اتفاقية فيما بينها، تقضي بإيداع كلٍٍ منها حصة يُتْفَق عليها، تُنستب إلى ودائعها من العملات الحرّة من غير حسابات الاستثمار؛ أي من الحسابات الجارية وما يأخذا حكمها، فتستخدم

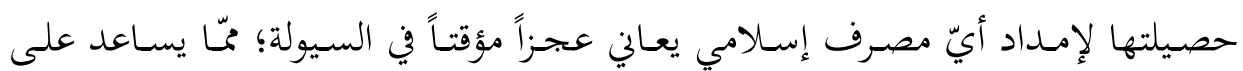
تخطّي هذا العجز، وذلك في صيغة قرض حسن من دون فوائد، ويُفضَّل ألا تتجاوز مدّة

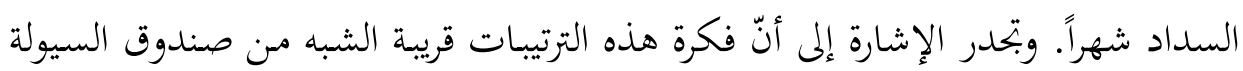
إلا في أمرين، هما: وجود القرض بالعملة الأجنبية، وإدارته على المستوى الدولي، انتفاعاً بإمكانيات السيولة التي يمكن توفيرها للمصارف الإسلامية خارج الدولة.

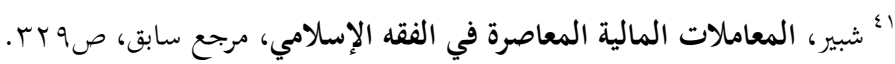

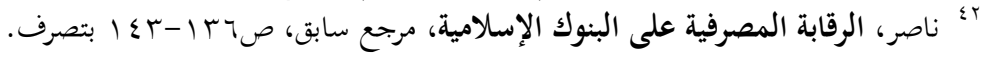




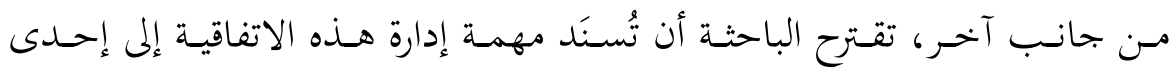

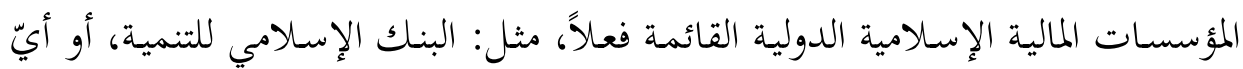

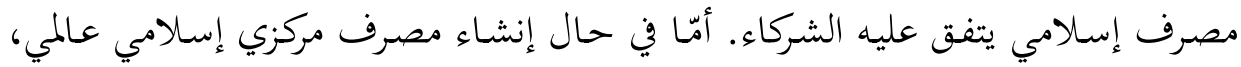

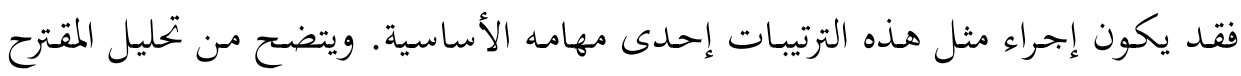

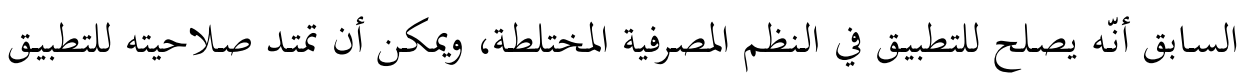
في النظم المصرفية الإسلامية. آع النه

نستخلص مثّا سبق وجود عدد من البدائل القابلة للتطبيق، التي تصلح لأداء المقصود

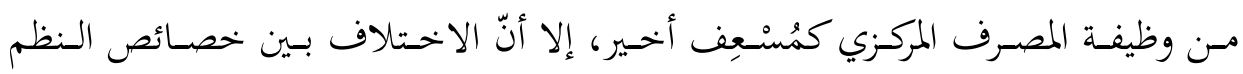

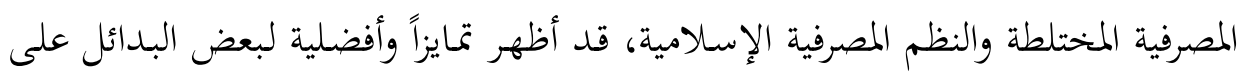

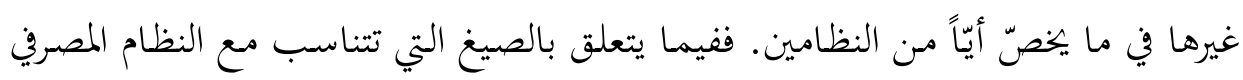

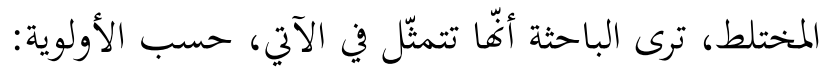
تخصيص نسبة الاحتياطي النقدي المقابلة لحسابات الاستثمار. تأسيس الصندوق المشترك للسيولة على مستوى المصارف الإسلامية المحلية. وضع ترتيبات إمداد السيولة بين المصارف الإسلامية على المستويين: العربي، والإسلامي.

توفير السيولة في إطار صيغة المضاربة، وبشروط حساب الاستثمار العام.

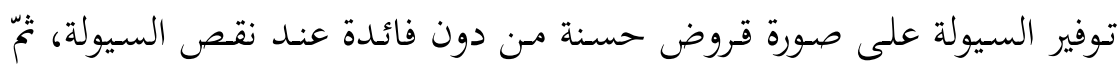
ردّها عند تحسّن السيولة. وفي حال كانت هناك صعوبات في تطبيق هذه البدائل، فإنّ الأمر يحتم إيجاد أدوات

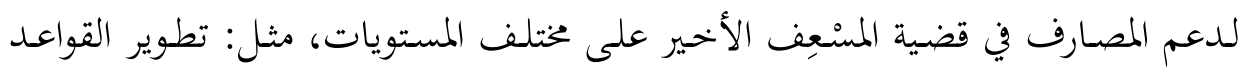

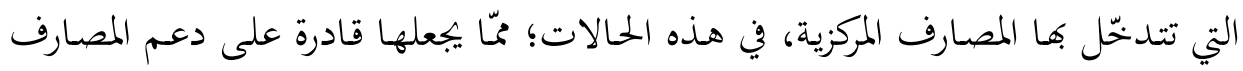

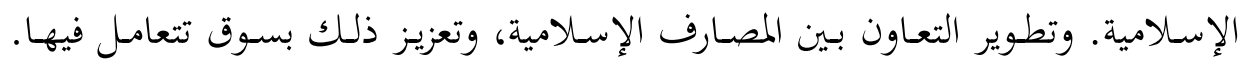


ومهمة تطوير الأدوات ووسائل الاتصال والبدائل المقترحة مع المصارف المارفي المركزية، تقع أولاً

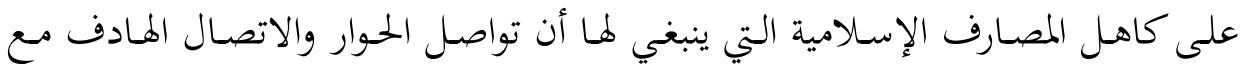

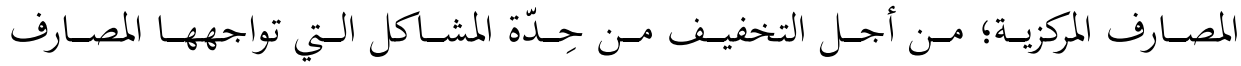

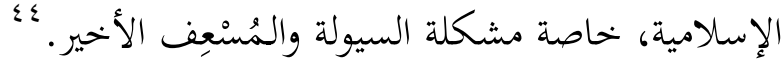

\section{رابعاً: انعكاسات المُسنعِف الأخير على الفرد والمجتمع}

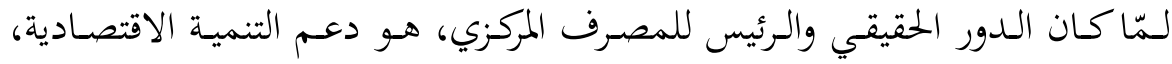

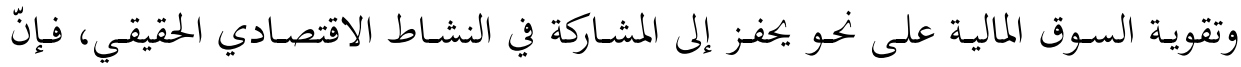

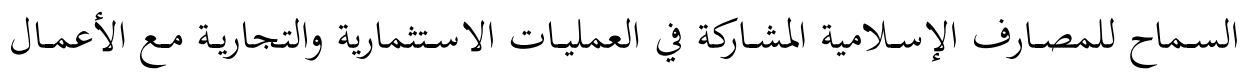

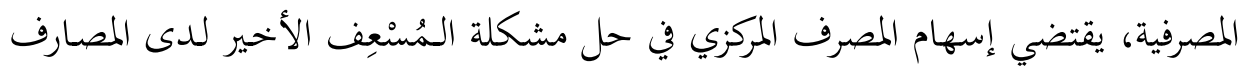

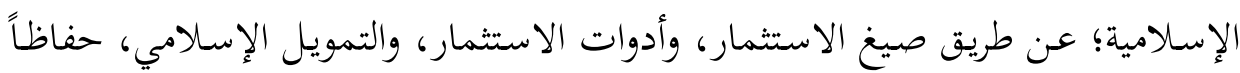

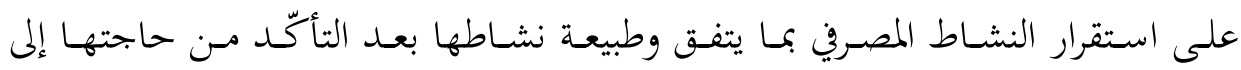

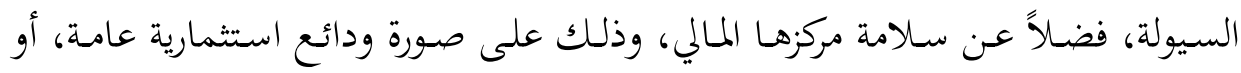

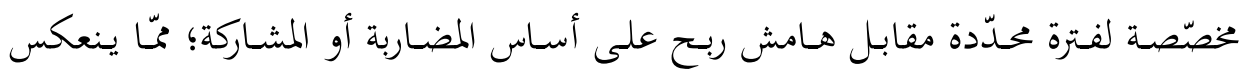

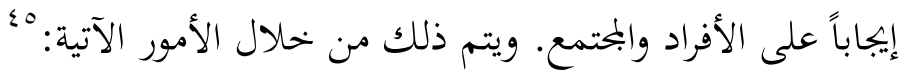

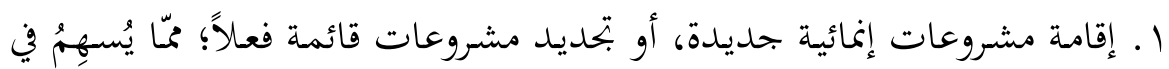

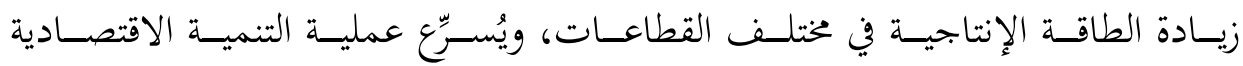

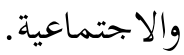

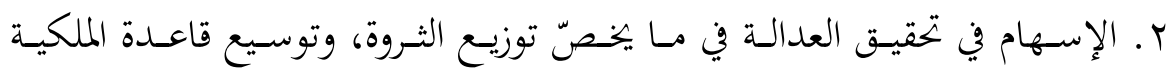

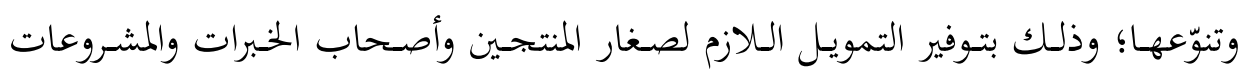

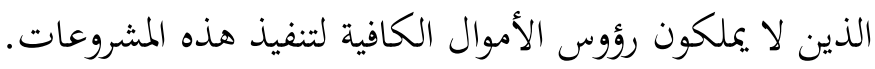

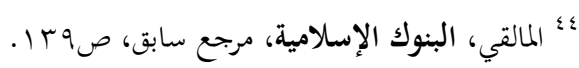

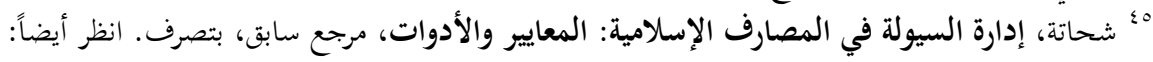

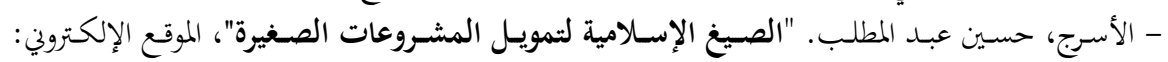

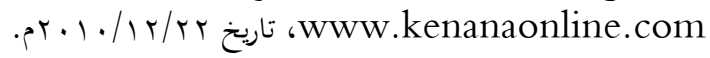

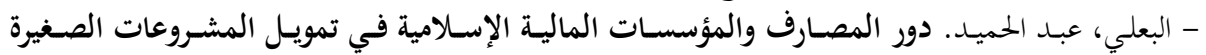

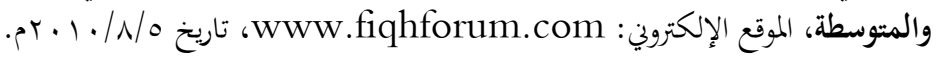


r. الاعتماد على الموارد المحلية في توفير فرص عمل للمهنيين والحرفيين. ع. تخصيص الموارد الاقتصادية واستغلالها؛ إذْ تتميّز صيغ التمويل الإسلامي بالتنوّع

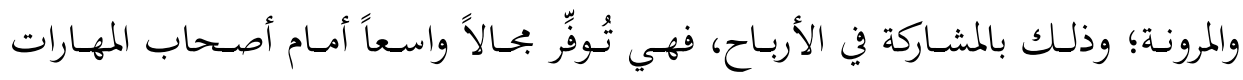

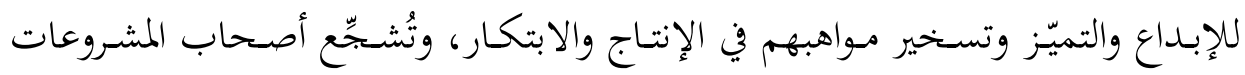

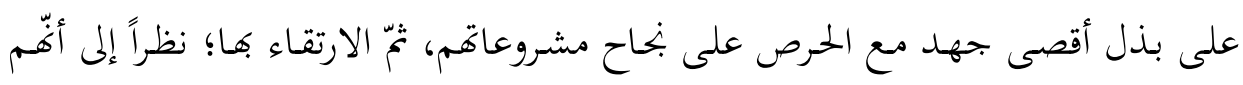
شركاء في الربح الناتج، وبذلك نضمن آلية ماهرة لتخصيص الموارد على أساس الكفاءة والمهارة والأمانة.

هـ التعاون والتضامن الاقتصادي المرغوب بين القطاعين: العام، والخاص؛ مـا يُسهِهُ في تحسين المناخ الاستثماري، وزيادة القيمة المضافة إلى الدخل القومي؛ وذلك عن طريق مشاركة أفرادِ المحتمِِ الدولةَ في مشروعاتِا الإنمائية. 7. التناغم مع الخطط الاقتصادية للدول، والعمل على دعمها بقصد تحقيق أهداف

V. تـوفير الـدعم والتـدريب اللازمسين لأفـراد المجتمـع، وتـوجيهـم إلى كيفيـة إنشـاء المشروعات الاقتصادية؛ بغية رفع المستوى المهني للموارد البشرية. م. تفعيل الدور المشترك بين المصارف المركزية والمصارف الإسلامية. 9 . إيجاد فرص عمل لشريحة واسعة من أفراد البحتمع؛ للحدّ من البطالة. • ا. ضمان القيم الإنسانية المشتركة لأفراد المحتمع، واحترام الذات، والإغناء المعرفي للحرفيين والمهنيين.

\section{خامساً: هيئة التأمين على الودائع}

إنّ ظهور ما يُسمّى هيئة التـأمين على الودائع وصندوق تعويض الخسـائر، قد أدّى

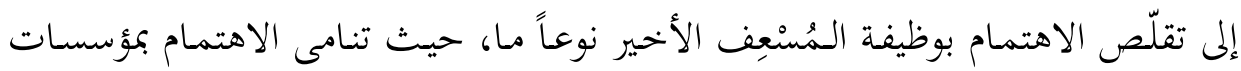

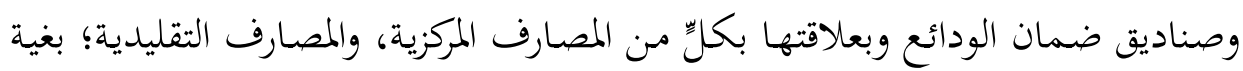


تدعيم التكامل والتعاون فيما بينهما، وصولاً إلى تعزيز الثقة بالجهاز المصرفي، ودفع عجلة

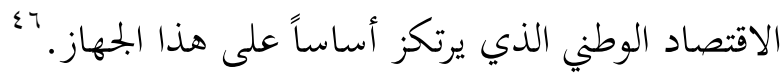
ففي الولايات المتحدة مثلاً، أُشنئت مؤسسة ضمان الودائع الفيدرالية عام بسو ام (FDIC) Federal Deposit Insurance Corporation

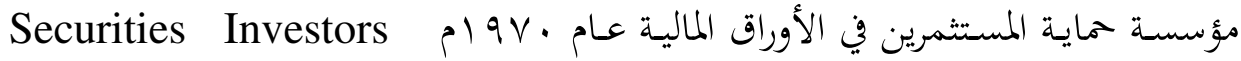
Protection Cooperation $\quad$ (SIPC)

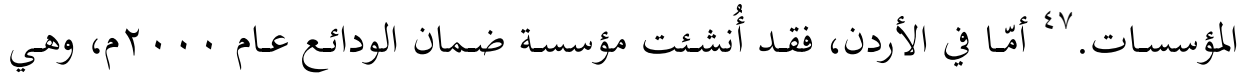

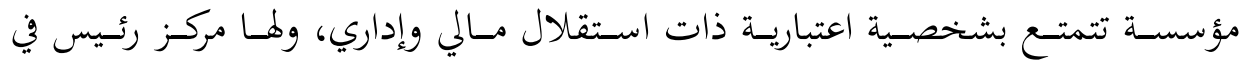
العاصمة عمّان، ويمكن فتح فروع لها في مختلف أنحاء المملكة. وتمدف هذه المؤسسة إلى

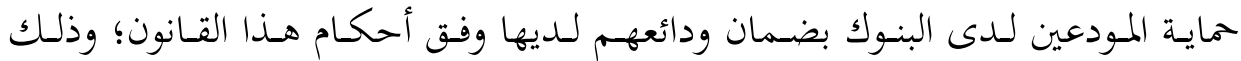

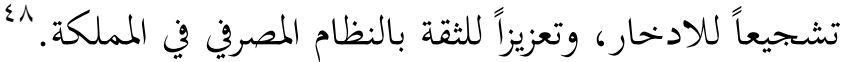

إنّ أبرز مشكلة تتسبّب فيها أنظمة تأمين الودائع، هي مشكلة ما يُعَرَف بالأخطار

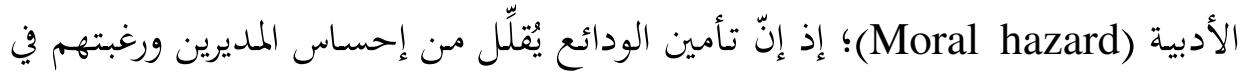

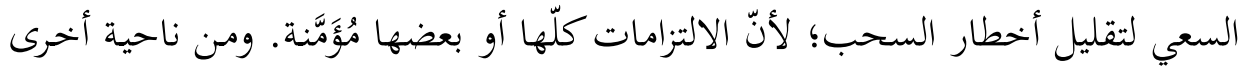
تستطيع المصارف الاقتراض بأسعار تقترب من أسعار الفائدة الخالية من الأخطار، ويتولّد

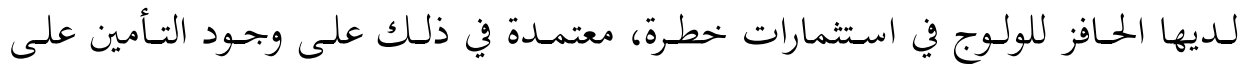

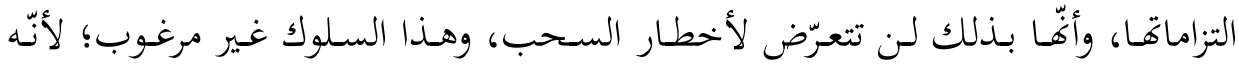

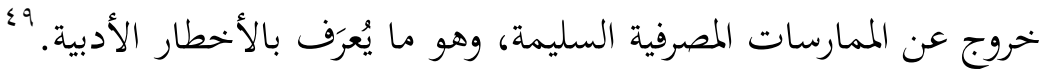
أمّا بالنسبة إلى النظام المصرفي الإسـلامي القـائم على المشـاركة، فعليـه مسؤولية في

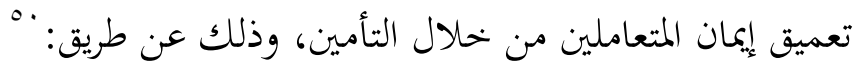

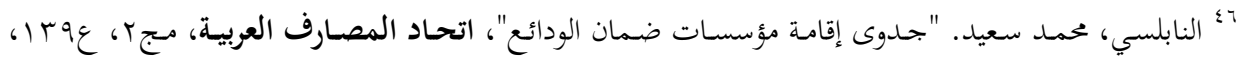

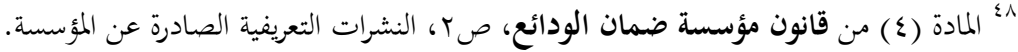

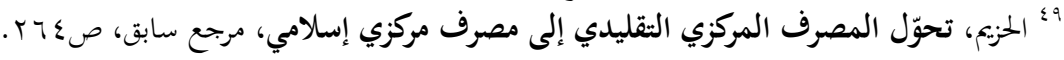

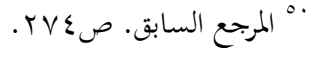




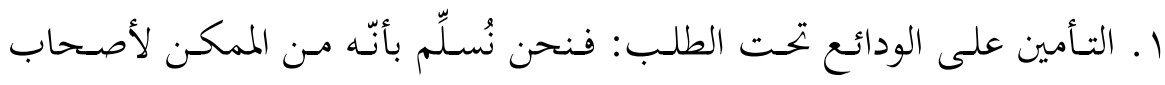

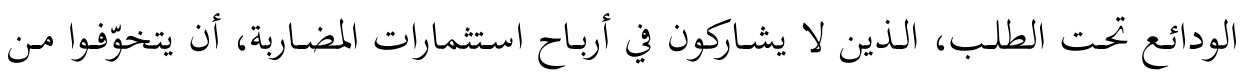

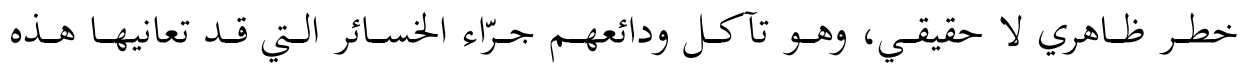

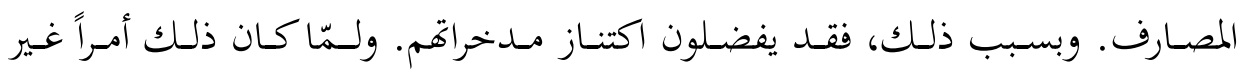

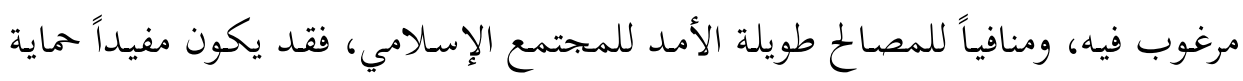

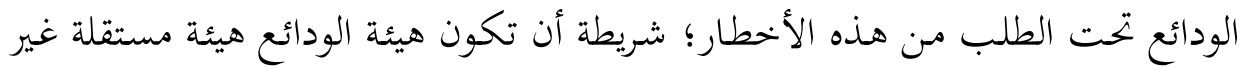

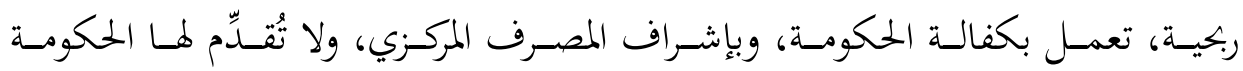

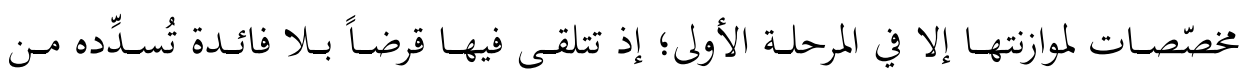

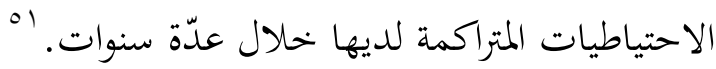

r. التأمين على ودائع المضاربة: يمكن لهيئة تأمين الودائع أن تُنشِئ صندوقاً خاصّاً

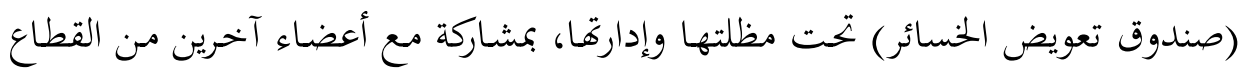

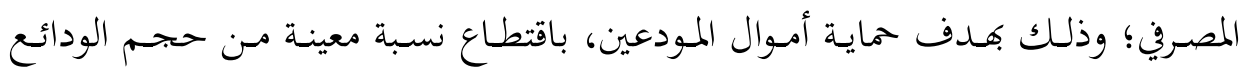

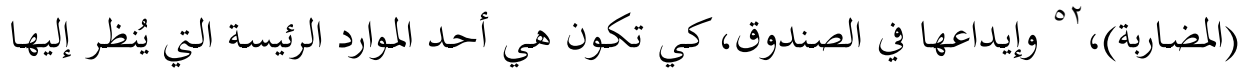

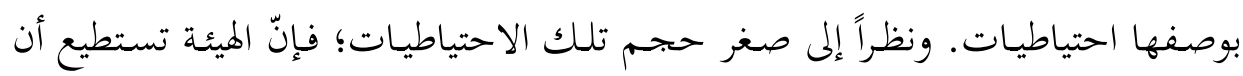

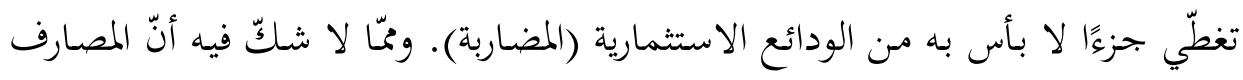

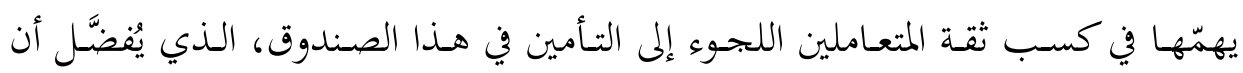

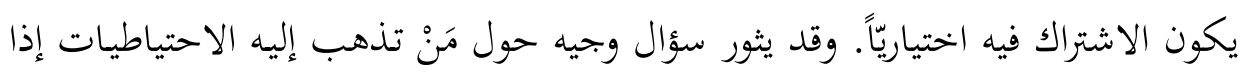

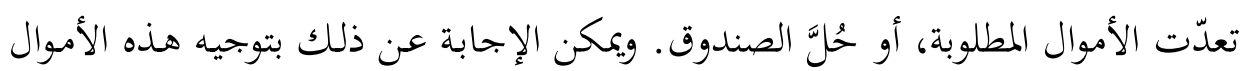
إلى الأعمال الخيرية في الدولة مثلاً.

إنّ صسندوق تعويض الخسـائر قـد يجابـه بـاعتراض مفـاده أنّ مصـادره هي مصـادر

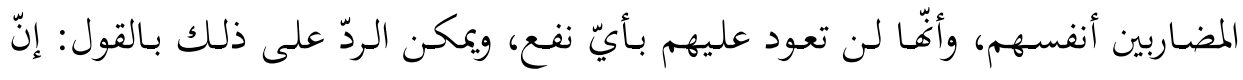

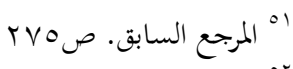

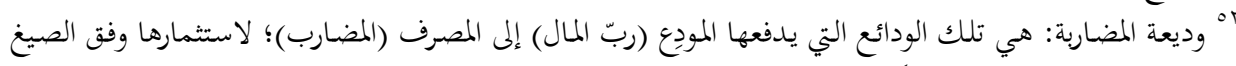

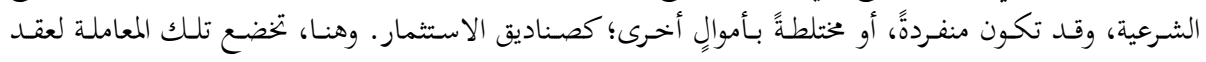


هناك مصلحة شرعية من تدعيم نظام المشاركة والمضاربة الإسلامية، ولا بُدّ لأفراد المجتمع

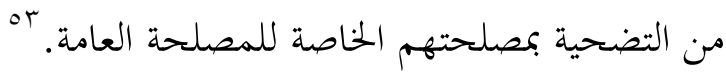

خاتمة:

لعلّه مـن أهـم وظـائف المصرف المركزي بتحاه المصـارف التقليدية وبعض المؤسسـات المالية، توفير الدعم المالي لما؛ بمعنى تمويل حالات العجز المفاجئ في السيولة، بحيث يتم هذا التمويل على أسس ربوية. وقد أظهرت هذه الدراسة أنّ المصارف الإسلامية لم بحد -حتى الآن- مَنْ يقوم بـدور الـمُسْعِفِ الأخير في حالة نقص السيولة لديها بمـا ينسجم مع الشريعة الإسلامية. فالمُسنعِف الأخير بالنسبة إلى المصارف الإسهامية هو قيام البنك

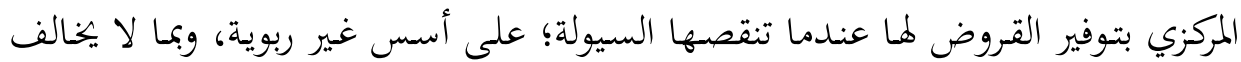
قواعد الشريعة، وذلك لمساعدة هذه المصارف على تقديم خحدماتما لعملائها، والاستمرار في أداء دورها الاقتصادي والاجتماعي. ودئ.

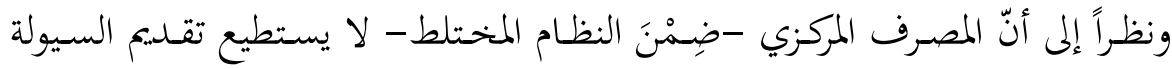

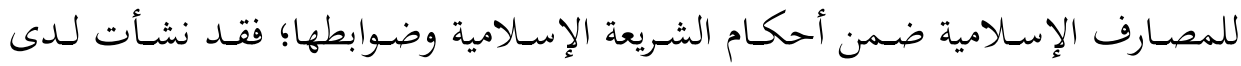
المصارف الإسلامية مشكلة المُسنعِف الأخير، الأمر الذي دفعها إلى الحذر والتحوّط من أخطار السيولة، عن طريق الاحتفـاظ بسيولة مرتفعة لـديها، وعـدم دخهول مشروعات طويلة الأجل. وقد أسهم عدم تعرّض هذه المصارف لمشكلة نقص السيولة في استمرار

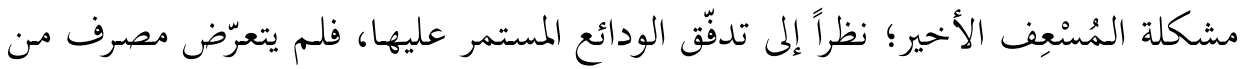
هذه المصارف لمشكلة النقص في السيولة، محّا أدى إلى عدم الإفادة من بعض التسهيلات

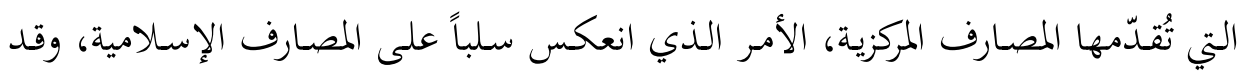
تمثّل ذلك في الحدّ من قدرة المصارف الإسلامية على استغلال مواردها بصورة أفضل، ميّا

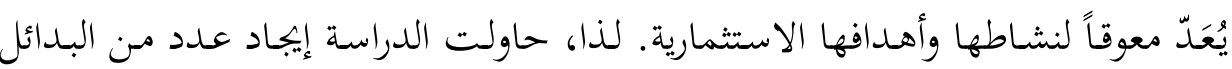
القابلة للتطبيق، التي تتيح للمصرف المركزي الاضطلاع بوظيفة المُسْعِف الأخير.

ror الحزي، تحوّل المصرف المركزي التقليدي إلى مصرف مركزي إسلامي، مرجع سابق، صب؟؟. 


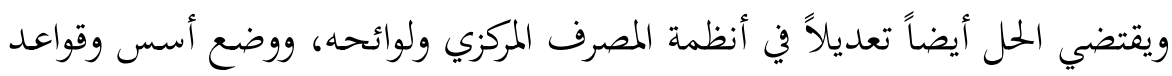

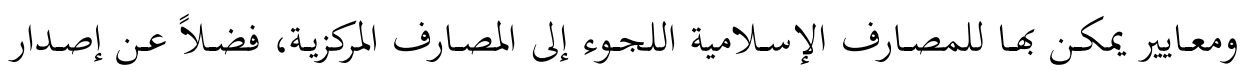

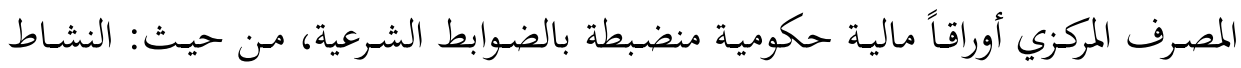

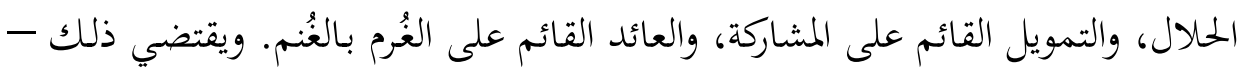

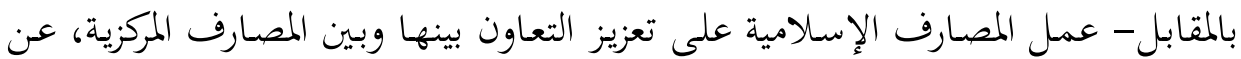
طريق تطوير الأدوات ووسائل الاتصال بينها.

وبما أنّه يصعب التنبّؤ بالمستقبل على نهوِ دقيق، فإنّ السيولة النقدية في المصارف

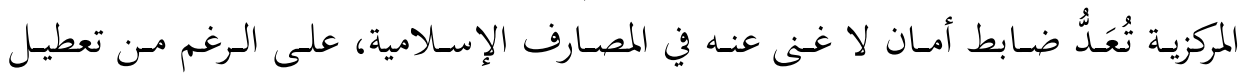
الأموال إلى حين حل مشكلة المُسنعِف الأخير. وقد يكون مفيداً أن نُدَّرّ بأنّ الدراسة لم تحاول طرح جميع بدائل المُسِْْفِ الأخير.

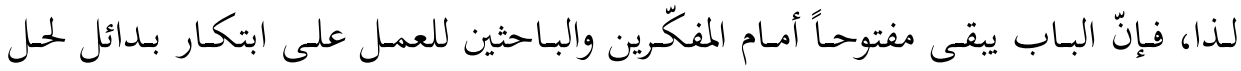

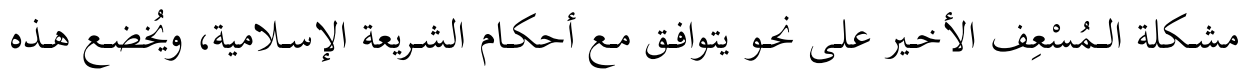

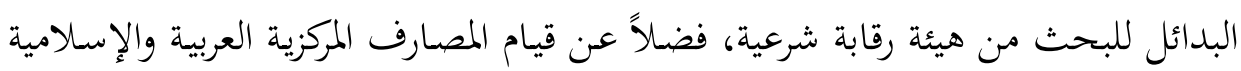

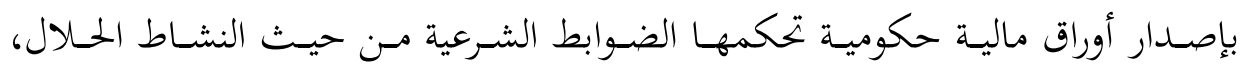

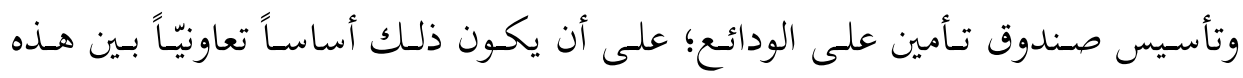
المصارف، وبمنأى عن آلية سعر الفائدة. 